\title{
Cultivation of hierarchical 3D scaffolds inside a perfusion bioreactor: scaffold design and finite-element analysis of fluid flow
}

\author{
Kaylie Sampson ${ }^{1}$. Songmi Koo ${ }^{1}$. Carter Gadola ${ }^{2}$. Anastasiia Vasiukhina ${ }^{1}$ Aditya Singh ${ }^{1}$ - Alexandra Spartano ${ }^{1}$. \\ Rachana Gollapudi ${ }^{1} \cdot$ Matthew Duley ${ }^{3} \cdot$ Jens Mueller ${ }^{4} \cdot$ Paul F. James $^{2} \cdot$ Amy M. Yousefi $^{1}$ (D)
}

Received: 26 June 2021 / Accepted: 8 November 2021

Published online: 24 November 2021

(c) The Author(s) $2021 \quad$ OPEN

\begin{abstract}
The use of porous 3D scaffolds for the repair of bone nonunion and osteoporotic bone is currently an area of great interest. Using a combination of thermally-induced phase separation (TIPS) and 3D-plotting (3DP), we have generated hierarchical 3DP/TIPS scaffolds made of poly(lactic-co-glycolic acid) (PLGA) and nanohydroxyapatite (nHA). A full factorial design of experiments was conducted, in which the PLGA and $\mathrm{nHA}$ compositions were varied between $6-12 \% \mathrm{w} / \mathrm{v}$ and $10-40 \% \mathrm{w} / \mathrm{w}$, respectively, totaling 16 scaffold formulations with an overall porosity ranging between $87 \%-93 \%$. These formulations included an optimal scaffold design identified in our previous study. The internal structures of the scaffolds were examined using scanning electron microscopy and microcomputed tomography. Our optimal scaffold was seeded with MC3T3-E1 murine preosteoblastic cells and subjected to cell culture inside a tissue culture dish and a perfusion bioreactor. The results were compared to those of a commercial CellCeram ${ }^{\text {tm }}$ scaffold with a composition of $40 \%$ $\beta$-tricalcium phosphate and $60 \%$ hydroxyapatite ( $\beta$-TCP/HA). Media flow within the macrochannels of 3DP/TIPS scaffolds was modeled in COMSOL software in order to fine tune the wall shear stress. CyQUANT DNA assay was performed to assess cell proliferation. The normalized number of cells for the optimal scaffold was more than twofold that of CellCeram ${ }^{\text {Tm }}$ scaffold after two weeks of culture inside the bioreactor. Despite the substantial variability in the results, the observed improvement in cell proliferation upon culture inside the perfusion bioreactor (vs. static culture) demonstrated the role of macrochannels in making the 3DP/TIPS scaffolds a promising candidate for scaffold-based tissue engineering.
\end{abstract}

\section{Article highlights}

- A design of experiments to generate 16 scaffold architectures and compositions, featuring both micropores and macrochannels, so as to provide an ideal environment for bone regeneration;

- The step-by-step fabrication process, examining the internal structures, and the simulation of fluid flow
(COMSOL) to supply adequate mechanical stimulation during bioreactor cultivation;

- The DNA content for the cell-seeded scaffolds over time (culture dish vs. a bioreactor), compared with a commercial scaffold featuring a similar porosity and pore size range.

Keywords Phase separation · 3D-plotting · COMSOL simulation · Perfusion bioreactor · Design of experiments

Supplementary Information The online version contains supplementary material available at https://doi.org/10.1007/s42452-02104871-3.

$\triangle$ Amy M. Yousefi, yousefiam@miamioh.edu | 'Department of Chemical, Paper and Biomedical Engineering, Miami University, $650 \mathrm{E}$ High Street, Oxford, OH 45056, USA. ${ }^{2}$ Department of Biology, Miami University, Oxford, OH 45056, USA. ${ }^{3}$ Center for Advanced Microscopy and Imaging, Miami University, Oxford, OH 45056, USA. ${ }^{4}$ Research Computing Support, Miami University, Oxford, OH 45056, USA.

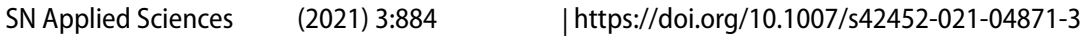




\section{Introduction}

Age is one of the primary determinants of osteoporosis. In the United States, over $30 \%$ of individuals 80 or older have osteoporosis, and osteoporosis is the primary cause of spine and hip fracture within this age group [1]. Postmenopausal women are particularly susceptible to osteoporosis, with women over 80 years accounting for $30 \%$ of fragility fractures and $60 \%$ of all hip fractures [1]. Other diseases that may impact bone density or fracture healing, such as diabetes mellitus [2], also contribute to the occurrence of fracture. Nonunion or malunion may occur in anywhere from $1.9-46 \%$ of fractures $[3$, $4]$, depending on fracture site and degree of injury of adjacent soft tissue, among other factors. Bone nonunion may be treated with bone autograft, allograft, or site stimulation if non-operative techniques are unsuccessful [4]. All these treatment modalities have risks and may have fairly high rates of failure depending on the microenvironment surrounding the fracture [3].

Due to the high rates of failure of many clinically used treatments for bone nonunion, many researchers have turned to the field of tissue engineering, and specifically to the creation of three-dimensional (3D) porous scaffolds. The goal of these implantable 3D scaffolds is to provide an optimal microenvironment for native cell proliferation. An ideal scaffold would provide mechanical support as well as physical and biochemical stimuli to stimulate optimal cell proliferation and function [5]. Typically, a 3D scaffold used for tissue engineering would be biocompatible, porous, and biodegradable. In the past, bioinert materials were widely used in clinical applications-such as temporary pedicle screws used to augment lumbar fusion-but these materials would not degrade in vivo and as such would either remain in the body or require a second surgery for removal [6]. Biodegradable scaffolds, however, are intended to provide mechanical support and optimal proliferation conditions for native cells during the healing process, then degrade as native tissue fills in the defect. In bone tissue engineering, the biodegradable material must stimulate bone tissue regeneration and repair, then degrade into non-toxic products that can be naturally metabolized or removed by the body [7].

In clinical settings, the tissue engineering approach aims to develop bioengineered tissues that meet patient requirements in terms of shape, size, and immunological compatibility, while minimizing the need for further clinical interventions. The clinical success of bioengineered tissues largely depends on scaffold composition and the ability of scaffold materials to serve as cell delivery vehicles and support suitable cell types [8]. The field of bone tissue engineering has grown exponentially over the past two decades. Bone scaffolds are intended to fill bone voids and support the body's intrinsic potential for regenerating bone tissues [9]. It is anticipated that bone tissue engineering will play a key role in orthopedic trauma and fracture care, whether by stimulating fracture healing in routine injuries or through addressing the unmet challenges of bone nonunions or bone defects of critical size [10].

In a recent review paper, Xue et al. have provided an overview of the current strategies for promoting bone healing using biomolecules, with a focus on bioactive actors incorporated into the modulated biomaterials for bone tissue engineering applications [11]. Furthermore, Hutmacher et al. have discussed the rationale for tissue engineering strategies and offered an overview of the recent efforts in developing personalized, clinically relevant in vitro and in vivo models of human diseases [12]. Bone tissue engineering has also shown promise in the treatment of temporomandibular joint disorders [13]. This includes several recent studies that have made use of 3D scaffolds for guided bone regeneration in maxillary and mandibular defects [14-16].

Poly (lactic-co-glycolic acid) (PLGA) is a commonly used material in tissue engineering due to its ease of processing in various conventional scaffold manufacturing techniques and controllable biodegradability. PLGA and other saturated poly(a-hydroxy esters) undergo hydrolytic degradation through de-esterification, then the products of this degradation are removed by natural processes. The degradation properties of PLGA are dependent on chain composition, hydrophobic/hydrophilic balance, and crystallinity. These factors can be changed by varying the ratios of PLA and PGA monomers [17]. Due to its poor osteoconductive properties and mechanical strength, PLGA is typically used with other materials such as ceramics in order to increase osteoconductivity and make it more suitable for bonecontacting applications. Hydroxyapatite $(\mathrm{HA})$ is a ceramic material regularly used in bone tissue engineering due in part to its chemical similarity to the mineral phase of bone. Unlike PLGA, HA has good osteoinductive and osteoconductive capabilities $[18,19]$. A composite scaffold using a polymer and a ceramic is somewhat biomimetic of natural bone tissue, due to the presence of polymeric proteins and mineral phases in the natural bone matrix. As an example of clinical applications, scaffolds made of PLGA and calcium phosphates ( $\mathrm{CaP}$ ) have been used in maxillofacial surgeries in human patients to maintain alveolar bone height following tooth extraction [15].

The high metabolic activity of bone cells limits the size of scaffold-tissue constructs that can be cultured in bone tissue engineering. We have used hierarchical 3D scaffolds made of PLGA and nanohydroxyapatite (nHA) to enhance 
the diffusion of oxygen and nutrients throughout our 3D scaffolds. These scaffolds were fabricated by combining 3D-plotting (3DP) and thermally-induced phase separation (TIPS). While the TIPS method generates micropores for oxygen and nutrient supply, the 3DP technique produces macrochannels for cell migration and bone ingrowth. We have used a full factorial design of experiments (DoE) to find the combination of PLGA\% and $\mathrm{nHA} \%$ that produce highly porous scaffolds (porosity $>85 \%$ ). These scaffolds were seeded with MC3T3-E1 preosteoblastic cells and cultured under static and dynamic conditions.

A perfusion bioreactor is essential to supporting the development of bone tissue. If a tissue scaffold is placed in a static medium and allowed to grow, diffusion will be the driving force in delivering nutrients and removing waste from the seeded cells. While this is similar to how cells in the body transport materials, the maximum distance of a cell from its nearest capillary rarely exceeds $200 \mu \mathrm{m}$ and is usually less than $100 \mu \mathrm{m}$ [20]. As a result, this will cause the majority of cell activity to be present on the surface of the scaffold due to difficulty in transport to the inside structure of the scaffold. The cells present closer to the center of the scaffold will not be able to engage in diffusion as effectively, and will die. As such, a perfusion bioreactor can address these setbacks by using convective transport to provide increased mass transport to the interior of the scaffold while permitting regulation of other parameters such as $\mathrm{pH}$, temperature, and nutrient concentration [21]. Specifically, for bone tissue cells, the mixing and fluid shear stress induced by perfusion will improve development by mechanically stimulating the cells, allowing them to differentiate into the desired cell type. In this study, dynamic cultures were performed on PLGA/nHA composite scaffolds in perfusion bioreactors.

In our previous studies $[22,23]$, we used an I-optimal design of experiments to maximize the porosity while approaching a compressive modulus of $\sim 5 \mathrm{MPa}$ for our 3DP/TIPS scaffolds. This was accomplished by analyzing a combination of PLGA concentration $(8 \%, 10 \%$, and $12 \% \mathrm{w} / \mathrm{v}), \mathrm{nHA}$ content $(0 \%, 10 \%$, and $20 \% \mathrm{w} / \mathrm{w})$, TIPS quenching temperature $\left(-20^{\circ} \mathrm{C},-10^{\circ} \mathrm{C}\right.$, and $\left.0{ }^{\circ} \mathrm{C}\right)$, and the diameter of macrochannels $(300 \mu \mathrm{m}, 380 \mu \mathrm{m}$, and $460 \mu \mathrm{m})$. In this study, we have narrowed down the quenching temperature to $-10^{\circ} \mathrm{C}$ and the diameter of macrochannels to $380 \mu \mathrm{m}$ based on our previous findings $[22,23]$. This work uses a full factorial design of experiments to investigate the combined role of PLGA concentration $(6 \%, 8 \%, 10 \%$, and $12 \% \mathrm{w} / \mathrm{v})$ and a broader range of nHA content $(10 \%, 20 \%, 30 \%$, and $40 \% \mathrm{w} / \mathrm{w})$ on the scaffold porosity and density.

This study also makes use of a longer quenching time inside the environmental chamber and a longer washing time inside the water bath, to enhance phase separation and to facilitate the extraction of sacrificial poly(ethylene glycol) (PEG) templates. The internal architecture of the scaffolds has been analyzed using scanning electron microscopy (SEM) and microcomputed tomography $(\mu \mathrm{CT})$. Our optimal 3DP/TIPS scaffold design [22, 23], reproduced using the extended TIPS quenching time and washing time, was seeded with MC3T3-E1 murine preosteoblastic cells and subjected to cell culture inside both a tissue culture dish and a perfusion bioreactor. A COMSOL analysis was performed in order to characterize the flow throughout the bioreactor, to fine tune the wall shear stress, and to determine how the presence of fluid flow may affect cell proliferation [18]. After being subjected to static and perfusion cell culture, the scaffolds were analyzed to determine cell proliferation using CyQUANT DNA assay. The results were compared to those of the commercial CellCeram ${ }^{\mathrm{Tm}}$ scaffold cultured under the same conditions. The role of fluid flow on cell differentiation will be the subject of our future study.

\section{Materials and methods}

\subsection{Materials}

Poly(lactic-co-glycolic acid) (PLGA, RESOMER ${ }^{\circledR}$ LG 824 S; I.V.=1.7-2.6 dl/g; with 82:12 lactide:glycolide ratio) was purchased from Evonik Biomaterials. Poly(ethylene glycol) (PEG, 35,000 Da), nHA (<200 nm particle size (BET), $\geq 97 \%$, synthetic), ethanol (EtOH), and 1,4-dioxane (ACS reagent, $\geq 99.0 \%$ ) were purchased from Sigma-Aldrich (St. Louis, MO, USA). Proliferation media was created by adding $50 \mathrm{ml}$ fetal bovine serum (FBS, Gemini), $5 \mathrm{ml}$ Glutamax (200 $\mathrm{mM}$ in $0.85 \% \mathrm{NaCl}$ ), $5 \mathrm{ml}$ amphotericin $B(250 \mu \mathrm{g} / \mathrm{ml})$, and $5 \mathrm{ml}$ Pen/Strep $(10,000$ units $/ \mathrm{ml}$ penicillin, $10,000 \mu \mathrm{g} / \mathrm{ml}$ streptomycin) (Gibco) to $500 \mathrm{ml}$ of a-MEM (-nucleosides,-ascorbic acid) (Gibco). Differentiation media was made by supplementing proliferation media with $50 \mu \mathrm{g} / \mathrm{ml}$ ascorbic acid (Sigma) and $10 \mathrm{mM} \beta$-glycerophosphate (Sigma). Scaffdex CellCeram ${ }^{\text {TM }}$ scaffolds $(60 \%$ hydroxyapatite, $40 \%$ $\beta$-tricalcium phosphate ( $\beta$-TCP), 83\% porosity, a diameter of $10 \mathrm{~mm}$ and a thickness of $3 \mathrm{~mm}$ ) were obtained from Sigma-Aldrich.

\subsection{D-plotting of PEG}

PEG was melt-processed using a 3D-Bioplotter (EnvisionTEC ${ }^{\mathrm{TM}}$, Germany) to produce the porous PEG sacrificial templates, as we have previously reported [24]. A plotting needle with an inner diameter of $400 \mu \mathrm{m}$ was used to produce a strand diameter of $\sim 380 \mu \mathrm{m}$, with a distance 
between strands of $\sim 1000 \mu \mathrm{m}$. Briefly, the PEG powder was dried for $24 \mathrm{~h}$ inside a glass desiccator connected to vacuum. Next, the powder was poured inside the 3D-plotting cartridge and heated to $115^{\circ} \mathrm{C}$. The needle was calibrated via dot printing using a camera to detect the location of the tip. The center-to-center distance between strands was set to $1380 \mu \mathrm{m}$. The cartridge containing PEG was inserted into the high temperature robot-head, and pressurized air was used to dispense PEG. A dispensing pressure of $1.5 \mathrm{bar}$ and a plotting speed of $2.1 \mathrm{~mm} / \mathrm{s}$ were used for 3D-plotting of PEG [24]. These PEG constructs served as sacrificial templates and were eventually extracted using deionized (DI) water to generate interconnected macrochannels within our PLGA/nHA scaffolds.

\subsection{Scaffold fabrication}

Table 1 lists the composition of the 3D scaffolds prepared in this study. PLGA was cryogenically ground using a Freezer Mill (Spex SamplePrep ${ }^{\mathrm{TM}}$ ) with a stainless-steel grinding mill operating at 10 cycles/s. The PLGA was subjected to a 5-min precool prior to grinding. The ground PLGA and nHA powder were weighed inside a 50-ml beaker, and then $6 \mathrm{ml}$ of 1,4-dioxane was added to the beaker. The solution was sonicated for $10 \mathrm{~min}$ at an amplitude of $20 \mu \mathrm{m}$, and then the beaker was covered with parafilm and placed inside a $60{ }^{\circ} \mathrm{C}$ water bath and stirred at $150 \mathrm{rpm}$. After $75 \mathrm{~min}$, these sonication and water bathing steps were repeated. A third sonication was performed, then the solution was allowed to cool down at room temperature for $10 \mathrm{~min}$. Four 3D-plotted PEG constructs were

Table 1 Composition of the scaffolds prepared for this study

\begin{tabular}{lcl}
\hline Scaffold number & $\begin{array}{l}\text { PLGA Concentration } \mathrm{C}_{1}(\%) \\
\mathrm{w} / \mathrm{v})\end{array}$ & $\begin{array}{l}\mathrm{nHA} \text { Concentra- } \\
\text { tion } \mathrm{C}_{2}(\% \mathrm{w} / \mathrm{w})\end{array}$ \\
\hline 1 & 12 & 40 \\
2 & 10 & 40 \\
3 & 8 & 40 \\
4 & 6 & 40 \\
5 & 12 & 30 \\
6 & 10 & 30 \\
7 & 8 & 30 \\
8 & 6 & 30 \\
9 & 12 & 20 \\
10 & 10 & 20 \\
11 & 8 & 20 \\
12 & 6 & 20 \\
13 & 12 & 10 \\
14 & 10 & 10 \\
15 & 8 & 10 \\
16 & 6 & 10 \\
\hline
\end{tabular}

positioned inside the beaker side by side, and the beaker was transferred to a ZP-16-1.5-H/AC Cincinnati Sub-Zero environmental chamber. An Erlenmeyer flask containing ethanol was also placed inside the chamber. The chamber was heated up to $40^{\circ} \mathrm{C}$ at a rate of $2{ }^{\circ} \mathrm{C} / \mathrm{min}$, maintained at this temperature for $5 \mathrm{~min}$, and then cooled down to $-10^{\circ} \mathrm{C}$ at a rate $1.5^{\circ} \mathrm{C} / \mathrm{min}$. After $150 \mathrm{~min}, 40 \mathrm{ml}$ of ethanol was added to the beaker. The ethanol was replaced after $48 \mathrm{~h}$. After $70 \mathrm{~h}$ at $-10^{\circ} \mathrm{C}$, the chamber was heated up to $20^{\circ} \mathrm{C}$ at a rate of $1.5^{\circ} \mathrm{C} / \mathrm{min}$.

The solidified construct containing PEG was removed from the beaker and dried on a sheet of aluminum foil for 90 min under a fume hood. The constructs were punched with a 10-mm biopsy punch to obtain four scaffolds. Then, the scaffolds were transferred to mesh biopsy bags and placed inside a water bath at $45^{\circ} \mathrm{C}$. After 3 days, the scaffolds were taken out, dried on a filter paper for $10 \mathrm{~min}$, placed inside $\mathrm{a}-80^{\circ} \mathrm{C}$ freezer for $1 \mathrm{~h}$, and freeze-dried for 3 days (Labconco). Then, the scaffolds were collected and stored inside a refrigerator at $4{ }^{\circ} \mathrm{C}$. The scaffold fabrication process is briefly illustrated in Fig. 1. Additionally, a set of TIPS-only scaffolds were fabricated using a PLGA concentration of $10 \%$ and an $\mathrm{nHA}$ concentration of $10 \%$. All of the previously-described TIPS steps were followed, but no PEG was embedded in the solution. These scaffolds were thinner $(\sim 3 \mathrm{~mm})$ and did not have the macrochannels present in the 3DP/TIPS scaffolds, and were used for comparison with the 3DP/TIPS scaffolds via SEM and $\mu C T$ imaging.

\subsection{Porosity calculation}

The following equation was used to calculate the porosity of the punched scaffolds:

$\varphi=100\left(\frac{V_{a}-V_{t}}{V_{a}}\right)$

where, $V_{a}$ is the apparent volume of the scaffold, calculated using the average of two diameter measurements and the thickness of the scaffold, and $V_{t}$ is the true volume of the scaffold, calculated based on the scaffold mass $(m)$ and solid matrix density $\left(\rho_{m}\right)$. The equation for $V_{t}$ is as follows:

$V_{t}=m / \rho_{m}$

Hence, the scaffold density $(\rho)$ and porosity $(\varphi)$ are related by the following equation:

$\rho=\rho_{m}(1-\varphi)$

The matrix density $\left(\rho_{\mathrm{m}}\right)$ of the scaffolds was estimated using the rule of mixtures and the weight percentage of $\mathrm{nHA}$ in the solid matrix $\left(C_{2}\right)$ as listed in Table 1: 


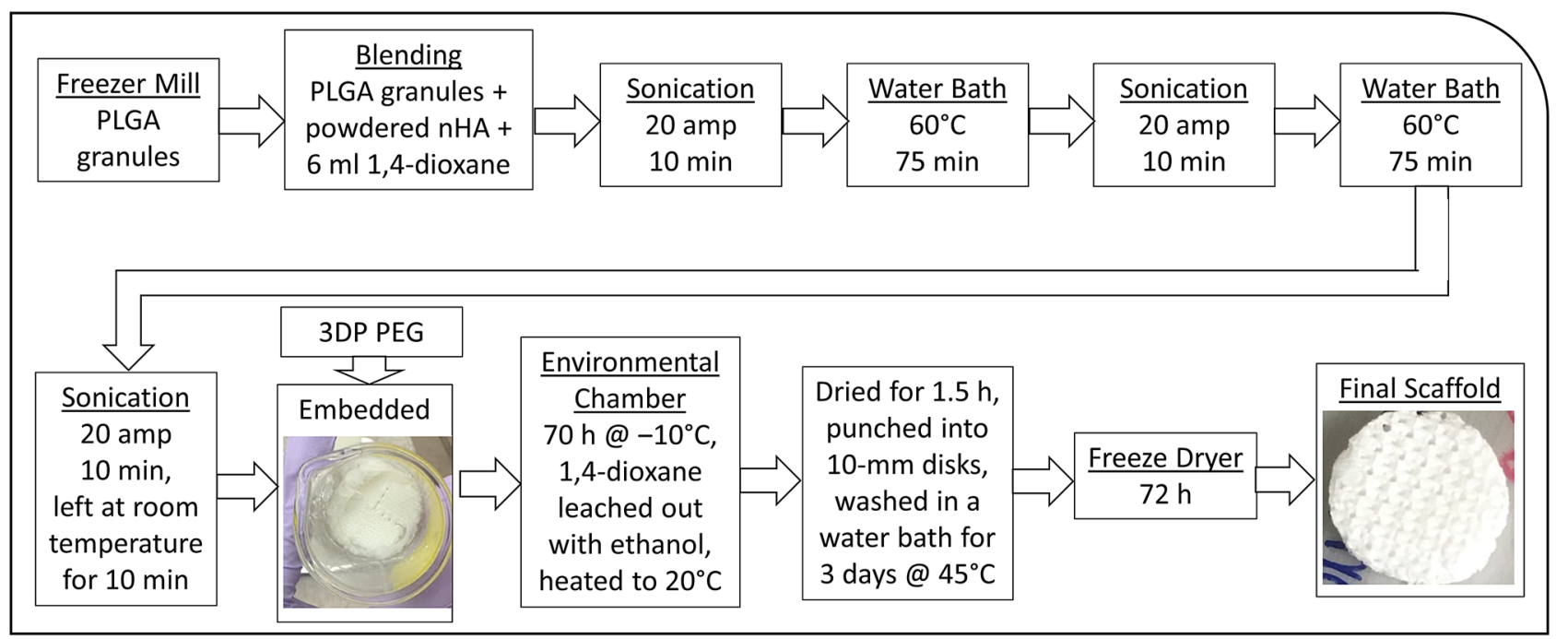

Fig. 1 The scaffold fabrication process utilizing the 3DP/TIPS technique

$\rho_{m}=\rho_{P L G A}\left(1-\frac{C_{2}}{100}\right)+\rho_{n H A}\left(\frac{C_{2}}{100}\right)$

where the density of PLGA $\left(\rho_{P L G A}\right)$ is $1.3 \mathrm{~g} / \mathrm{cm}^{3}$ and the density of $\mathrm{nHA}\left(\rho_{n H A}\right)$ is $3.16 \mathrm{~g} / \mathrm{cm}^{3}$ [18].

\subsection{Scanning electron microscopy (SEM)}

The scaffold samples were cut into quarters with a clean razor blade. A thin layer of epoxy was spread on an SEM stub. One quarter was mounted on the stub with the top up. A second quarter was mounted upside down. A third quarter was mounted on edge so the cut-side was up, allowing for imaging of the cut surface. All three pieces were mounted on the same stub. Silver paint was applied to the edges to ground the samples. Stubs were then sputter-coated with approximately $20 \mathrm{~nm}$ gold using Denton Desk II Sputter Unit and imaged using a Zeiss Supra ${ }^{\text {TM }} 35 \mathrm{VP}$ microscope at an accelerating voltage of $4 \mathrm{keV}$. For cellseeded scaffolds, the scaffolds were fixed in $1 \%$ glutaraldehyde/2\% paraformaldehyde in Dulbecco's phosphatebuffered saline (DPBS) for $1 \mathrm{~h}$, and then washed in DPBS four times at $5 \mathrm{~min}$ each. After a serial dehydration at 25 , 50, 75, 95 and 100\%, the scaffolds were critical-point dried in a Tousimis Samdri 780A (Tousimis, 2211). The dried samples were then mounted, silver painted, sputter-coated, and imaged the same as the non-seeded scaffolds.

\subsection{Microcomputed tomography $(\mu \mathrm{CT})$}

Specimens were placed in a 14-mm diameter holder and scanned using a Scanco Medical $\mu$ CT100 system. Scan settings were: voxel size $5 \mu \mathrm{m}, 55 \mathrm{kVp}$ energy, $109 \mu \mathrm{A}$, $0.5 \mathrm{~mm}$ AL filter, 1000 projections around $180^{\circ}$, average data of 3 and integration time of $500 \mathrm{~ms}$. The analysis was performed using the manufacturer's evaluation software, a threshold of 40 and 100 for 3DP/TIPS and TIPSonly scaffolds, respectively, and a threshold of 280 for the CellCeram ${ }^{\text {tm }}$ scaffolds (on a grayscale of 0-1000) to segment the scaffolds from air. A 4-mm-diameter cylindrical region of interest $(\mathrm{ROI})$ with a height of $0.5 \mathrm{~mm}$ centered on the midpoint was used for the scaffold. The Scanco CT machine was calibrated to a hydroxyapatite (HA) phantom and checked weekly. The machine thresholds of 40,100 , and 280 were equivalent to $-82.1 \mathrm{mg} \mathrm{HA} / \mathrm{cm}^{3}, 44.9 \mathrm{mg}$ $\mathrm{HA} / \mathrm{cm}^{3}$, and $426 \mathrm{mg} \mathrm{HA} / \mathrm{cm}^{3}$, respectively.

\subsection{Simulation of fluid flow inside the perfusion bioreactor}

The repetition of basic structures (unit cells) allows for a simple yet effective approach to scaffold design. Unit cells are systematically distributed throughout the internal geometry of a scaffold. These individual geometric units can be constructed using computer-aided design (CAD) tools and basic geometric primitives such as cubes, spheres, and cylinders/rods, then can be tested in a multiphysics modeling software such as COMSOL. The scaffold model for this study was designed to have a half-cylindrical structure containing layers of cylindrical rods. A target wall shear stress of $20 \mathrm{mPa}$ was selected for the model, as this value has been reported to supply adequate mechanical stimulation at the beginning of the cultivation process [25]; however, the shear stress is likely to increase as cells 
begin to fill the macrochannels. The flow rate of the culture media needed to achieve a shear stress of $20 \mathrm{mPa}$ was determined based on COMSOL Multiphysics simulations as described below. The simulated flow rate was then used to choose the speed of the peristaltic pump (in rpm) for the bioreactor experiments.

\subsection{Newtonian fluid flow model}

A laminar incompressible Newtonian flow model in COMSOL was used to simulate the fluid flow through the scaffold geometry. First, the model was validated by comparing the shear stress values computed in COMSOL at the wall of a simple cylinder to the values obtained analytically based on the equations for Newtonian pipe flow. For a pipe with a radius of $\mathrm{R}$ and a volumetric flow rate of $\mathrm{Q}$, the shear rate at the wall $\left(\gamma_{w}\right)$ can be described as:

$\gamma_{w}=\frac{4 Q}{\pi R^{3}}$

The shear stress at the wall $\left(\tau_{w}\right)$ is the product of the shear rate at the wall and the dynamic Newtonian viscosity $(\mu)$ :

$\tau_{w}=\mu \gamma_{w}$

By substituting Eq. 5 into Eq. 6, we get an expression that describes the shear stress exerted by the fluid on the wall:

$\tau_{w}=\mu\left(\frac{4 Q}{\pi R^{3}}\right)$

The fluid flowing through the model was specified as water with a density of $1000 \mathrm{~kg} / \mathrm{m}^{3}$ and a viscosity of $1 \mathrm{mPa}$.s. According to safety data sheets (SDS) for a MEM Alpha product, the density at room temperature for a typical culture media is $1038 \mathrm{~kg} / \mathrm{m}^{3}$ and the dynamic viscosity is $1.06 \mathrm{mPa}$.s. Therefore, water was considered to be a reasonable approximation for the culture media in this study [26]. The appropriate mesh discretization was selected by applying various mesh sizes in COMSOL (normal, fine, finer, extra fine and extremely fine) to the basic building block of a final scaffold geometry-namely a simple 3D cylinder with a length of $4 \mathrm{~mm}$ and a diameter of $400 \mu \mathrm{m}$-to replicate the length and the diameter of a macrochannel within a 3DP/TIPS scaffold. Then, the effect of different mesh sizes on the shear rate profile throughout the cylindrical construct was analyzed. Once the mesh selection was finalized, the model was scaled up to represent one half of the physical scaffold. The new prototype consisted of 38 inlet channels, oriented within a half-cylinder 4-mm-high and 10-mm-diameter. The cylindrical building blocks retained their $400-\mu \mathrm{m}$ diameter.

\subsection{Cell culture}

MC3T3-E1 cells from the American Type Culture Collection (ATCC.org) that were previously frozen at passage 4 were thawed by gentle agitation in a $37^{\circ} \mathrm{C}$ water bath for approximately $2 \mathrm{~min}$. The vials were removed from the water bath as soon as the contents were thawed and decontaminated by spraying with $70 \%$ ethanol. The thawed cell suspension was transferred to a centrifuge tube containing $9 \mathrm{ml}$ of proliferation media and spun down by centrifugation ( $300 \times \mathrm{g}$ for $5 \mathrm{~min}$ ). Then, $2 \mathrm{ml}$ of proliferation media was added to the tube to resuspend the pellet. This cell suspension was split equally between two $75 \mathrm{ml}$ tissue culture treated polystyrene flasks. The volume of each flask was brought to $15 \mathrm{ml}$ by addition of proliferation media. Flasks were labeled as passage \#1 and transferred to a $37^{\circ} \mathrm{C}, 5 \% \mathrm{CO}_{2}$ incubator. The proliferation media was replaced every $2-3$ days. When passaging the cells, all flasks were combined to ensure homogenous cell populations, then subsequently split into three new flasks per previous flask. Subconfluent cells were harvested by briefly incubating with $0.05 \%$ trypsin EDTA (Fisher Scientific) until cells had fully detached, then spun down. Cells were passaged once they reached $\sim 80 \%$ confluence according to supplier's specification.

\subsection{Scaffold sterilization}

The day before cell seeding, the scaffolds were sterilized in $40 \mathrm{ml}$ of $70 \%$ ethanol, with different scaffold formulations sterilized separately using the same technique. After incubating for 2-4 h, ethanol was removed and the scaffolds were washed three times with sterile DPBS ${ }^{++}$(Dulbecco's phosphate buffered saline, $\left.+\mathrm{Mg}^{++},+\mathrm{Ca}^{++}\right)$. The scaffolds were left to incubate in sterile $\mathrm{DPBS}^{++}$at room temperature. After 90 min the sterile $\mathrm{DPBS}^{++}$was aspirated out, and the scaffolds were rinsed twice more with $\mathrm{DPBS}^{++}$. Finally, $25 \mathrm{ml}$ of proliferation media was added, and the scaffolds were left to incubate overnight at room temperature.

\subsection{Cell seeding}

All cells were harvested after reaching $~ 80 \%$ confluency on the third passage. The proliferation media was discarded, and the cells were rinsed briefly with Dulbecco's phosphate-buffered saline solution without $\mathrm{Mg}^{++}$and $\mathrm{Ca}^{++}\left(\mathrm{DPBS}^{--}\right)$. The $\mathrm{DPBS}^{--}$was discarded and $4 \mathrm{ml}$ of $0.05 \%$ trypsin (Fisher Scientific) was added to each flask. Flasks were incubated at $37^{\circ} \mathrm{C}$ for $3-5$ min until cells had fully detached and $4 \mathrm{ml}$ of complete alpha MEM media was added. They were transferred to the centrifuge tube and centrifuged ( $300 \times \mathrm{g}$ for $5 \mathrm{~min}$ ). The cells were counted 
using a hemocytometer and the cell suspension was diluted to $3 \times 10^{6} / 100 \mu \mathrm{l}$ media. Sterilized scaffolds were transferred to the non-treated 24-well tissue culture plate using flame-sterilized forceps, and $100 \mu \mathrm{l}$ of cell suspension was placed on the top of each scaffold. The scaffolds were incubated at $37^{\circ} \mathrm{C}, 5 \% \mathrm{CO}_{2}$ for $2 \mathrm{~h}$ to allow the cells to penetrate the scaffolds, then $1 \mathrm{ml}$ of proliferation media was added to each scaffold and incubated overnight at $37^{\circ} \mathrm{C}, 5 \% \mathrm{CO}_{2}$. The following day (day 0), the proliferation media was replaced with $1 \mathrm{ml}$ osteogenic differentiation media. Day 0 scaffolds were harvested after addition of differentiation media.

\subsection{Bioreactor trials}

The 3DCulturePro ${ }^{\mathrm{Tm}}$ perfusion bioreactors (Fig. 2a) were obtained from TA Instruments. Before use, all surfaces of the bioreactors were washed with warm water and detergent. Then, all surfaces and connecting tubes of the bioreactors were washed with $70 \%$ ethanol and rinsed again with DI water. The disassembled bioreactors were left to dry for approximately $24 \mathrm{~h}$, then sealed inside sterile bags and autoclaved for $30 \mathrm{~min}$. After autoclaving, the bioreactors were reassembled under a laminar flow hood utilizing strict aseptic technique. The scaffolds were transferred one at a time to the bioreactors using flame-sterilized tweezers. Each scaffold was clamped inside a bioreactor, as shown in Fig. 2b, and the bioreactor was sealed. Approximately $100 \mathrm{ml}$ of sterile differentiation media was then injected into the bioreactor, and the system was hooked to a MasterFlex L/R pump (Cole-Parmer) set to circulate the media at $40 \mathrm{rpm}$. This pump speed was chosen to achieve a wall shear stress of $20 \mathrm{mPa}$ inside the scaffold macrochannels, as mentioned earlier, and yielded a mass flow rate of $0.2 \mathrm{~g} / \mathrm{s}$. All bioreactors were then moved to a $37{ }^{\circ} \mathrm{C}$ $5 \% \mathrm{CO}_{2}$ incubator. Every 7 days, $\sim 50 \mathrm{ml}$ of the differentiation media was removed and replaced with $\sim 50 \mathrm{ml}$ of fresh differentiation media.

\subsection{DNA content assay}

To prepare the scaffolds for DNA analysis, each scaffold was rinsed with DPBS $^{++}$twice. DPBS was aspirated out of the samples and scaffolds were quickly transferred to sterile tubes and stored at $-80^{\circ} \mathrm{C}$ until use. A CyQUANT cell proliferation assay kit (Life Technologies) was used to quantify the number of cells that had adhered to the scaffold. An RNAse/Lysis buffer was prepared using $1 \mathrm{ml}$ lysis buffer stock, $210 \mathrm{mg} \mathrm{NaCl}, 8.3 \mathrm{mg}$ EDTA, $7.5 \mu \mathrm{l}$ RNAse, and DI water to bring the volume to $20 \mathrm{ml}$. Additionally, a dye/ lysis buffer solution was prepared using $550 \mu$ l of buffer, $10.4 \mathrm{ml}$ of DI water, and $55 \mu \mathrm{l}$ of dye. All scaffold samples were removed from the freezer and placed on ice, then $1 \mathrm{ml}$ of RNAse/Lysis buffer was added to each sample. The scaffolds were vortexed, then sonicated using a Branson Sonifier 250 for $20 \mathrm{~s}$ at $50 \%$ duty cycle and 5 output to break apart the scaffold and lyse the cells. The sonicator tip was cleaned with DI water, then $70 \%$ ethanol, then DI water again after each sample. After sonication, all samples were vortexed, then incubated on ice for $1 \mathrm{~h}$, then
Fig. 2 a A diagram showing the path of media flow through the 3DCulturePro perfusion bioreactor, and $\mathbf{b}$ the assembled bioreactor with a scaffold clamped inside
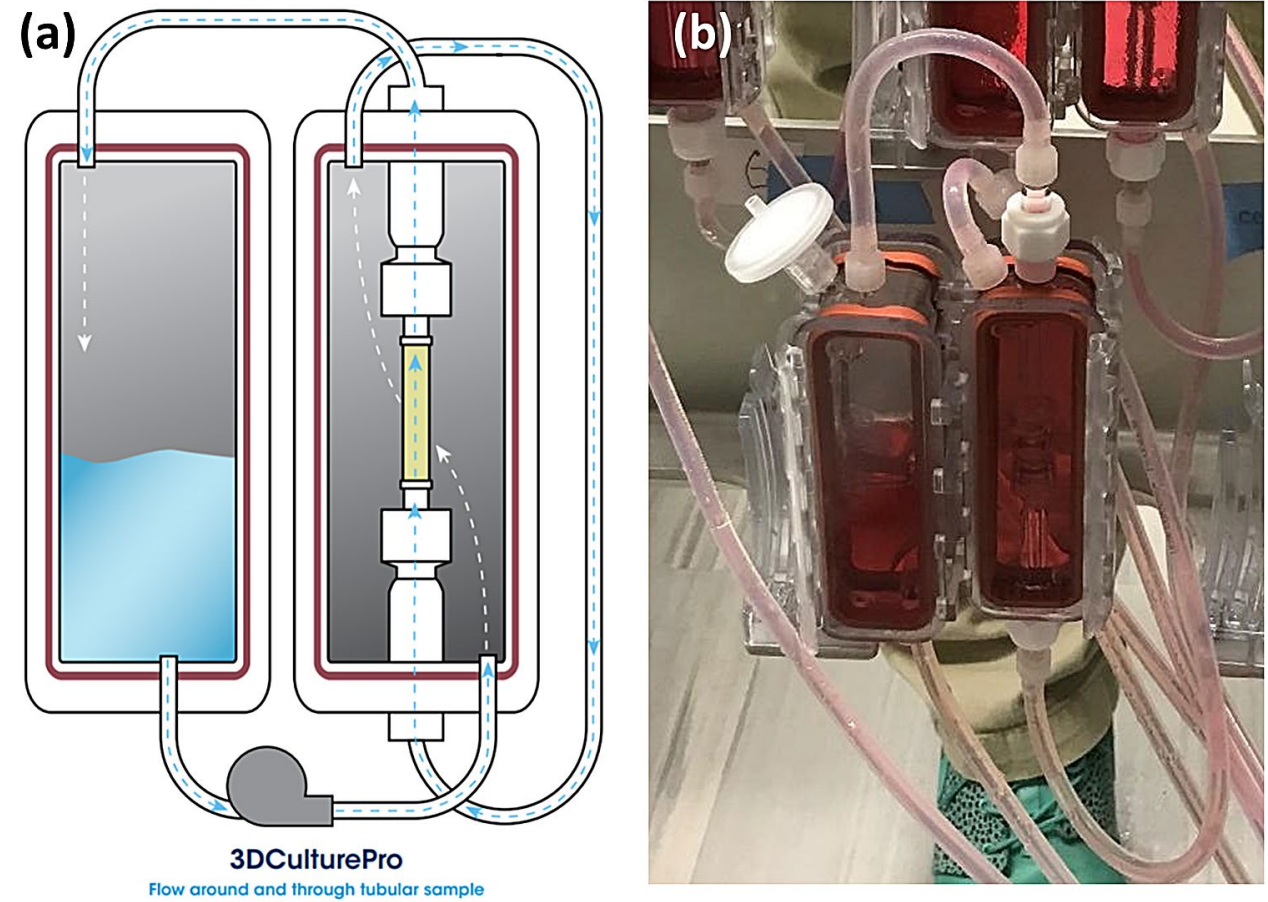
sonicated again for $10 \mathrm{~s}$. After the second sonication, the samples were vortexed again, then centrifuged to pellet out any pulverized scaffold and cell pieces.

Taking care not to disturb the pellet, different volumes $(100 \mu \mathrm{l}, 50 \mu \mathrm{l}, 25 \mu \mathrm{l})$ were taken from the top of each solution so that each scaffold sample could be run in triplicate. All wells were brought to $100 \mu \mathrm{l}$ by adding RNAse/ Lysis buffer. Blanks were created using $100 \mu$ l of RNAse/ Lysis buffer. Before fluorescence imaging, $100 \mu \mathrm{l}$ of dye/ lysis buffer was added to each well and gently mixed. After addition of the dye, the samples were imaged using $482 / 50$ excitation filter and a 528/20 emission filter on a NOVOstar cell-based fast kinetic microplate reader. Starting with one million MC-3T3-E1 cells, one-million cell standard was used, and serial dilutions were performed to create a standard curve.

\subsection{Statistical analysis}

The experimental data were presented as mean \pm standard deviation $(n=3$ or $n=4)$, represented by error bars in the graphs. The student's t-test was performed at a 95\% confidence interval using the Analysis ToolPak in Excel. The statistical analysis was used to verify the significance of differences between two sets of samples, and $p<0.05$ was considered statistically significant.

\section{Results}

\subsection{Scaffold characterization}

Table 2 shows the height, density, and porosity of each of the scaffold formulations in this study. These scaffolds showed porosities ranging between 87-93\%. As shown in Fig. $3 a$, the scaffold density increases as PLGA concentration increases (see Table 1). Moreover, the 3D surface plots shown in Fig. $3 \mathrm{~b}$ and $\mathrm{c}$ underline how the scaffold composition (nHA content and PLGA concentration) can influence the porosity and density of these scaffolds, respectively. The set of 16 scaffolds in this study includes an optimal scaffold designed in our previous study (scaffold 14 in Tables 1 and 2). This scaffold shows a porosity of $87.2 \%$, replicating the value reported in our previous work despite some changes in the scaffold fabrication process in the present study (prolonged TIPS quenching time and washing time). This scaffold was selected as the optimal formulation for the perfusion bioreactor trials. Scaffold \#14 had the
Table 2 The thickness, density, and porosity of the scaffolds listed in Table 1

\begin{tabular}{llll}
\hline $\begin{array}{l}\text { Scaffold } \\
\text { number }\end{array}$ & Thickness $(\mathrm{mm})$ & $\begin{array}{l}\text { Density } \\
\left(\mathrm{g} / \mathrm{cm}^{3}\right)\end{array}$ & Porosity (\%) \\
\hline 1 & $4.38 \pm 0.24$ & $0.201 \pm 0.019$ & $91.1 \pm 0.9$ \\
2 & $3.95 \pm 0.04$ & $0.222 \pm 0.014$ & $89.1 \pm 0.7$ \\
3 & $3.95 \pm 0.08$ & $0.198 \pm 0.009$ & $90.3 \pm 0.4$ \\
4 & $3.67 \pm 0.29$ & $0.168 \pm 0.013$ & $91.8 \pm 0.6$ \\
5 & $4.04 \pm 0.07$ & $0.211 \pm 0.040$ & $88.7 \pm 0.2$ \\
6 & $4.05 \pm 0.07$ & $0.198 \pm 0.011$ & $89.4 \pm 0.6$ \\
7 & $3.84 \pm 0.08$ & $0.187 \pm 0.017$ & $89.9 \pm 0.9$ \\
8 & $3.80 \pm 0.07$ & $0.148 \pm 0.003$ & $92.0 \pm 0.2$ \\
9 & $3.89 \pm 0.09$ & $0.200 \pm 0.010$ & $88.1 \pm 0.6$ \\
10 & $3.82 \pm 0.14$ & $0.187 \pm 0.028$ & $88.8 \pm 1.7$ \\
11 & $3.81 \pm 0.07$ & $0.150 \pm 0.012$ & $91.0 \pm 0.7$ \\
12 & $3.66 \pm 0.17$ & $0.141 \pm 0.017$ & $91.6 \pm 1.0$ \\
13 & $3.69 \pm 0.06$ & $0.181 \pm 0.011$ & $87.8 \pm 0.8$ \\
14 & $3.62 \pm 0.05$ & $0.190 \pm 0.005$ & $87.2 \pm 0.3$ \\
15 & $3.57 \pm 0.11$ & $0.189 \pm 0.019$ & $87.3 \pm 1.3$ \\
16 & $3.77 \pm 0.12$ & $0.135 \pm 0.015$ & $90.9 \pm 1.0$ \\
\hline
\end{tabular}

lowest porosity in this study, yet high enough to serve as a tissue engineering scaffold.

\subsection{Scanning electron microscopy (SEM)}

Figure 4a shows an SEM image of a 3D-plotted PEG template. The side views of a PLGA/nHA scaffold prepared using the TIPS-only method are shown in Fig. $4 \mathrm{~b}$ and $c$ for comparison with the 3DP/TIPS scaffolds. The majority of pores are below $100 \mu \mathrm{m}$ in size. Figure $4 \mathrm{~d}-\mathrm{f}$ show the side views of scaffold \#2 prepared using the 3DP/ TIPS method ( $40 \% \mathrm{nHA})$. Well-formed macrochannels are visible resulting from the removal of the sacrificial PEG template.

Figure $4 \mathrm{~g}$ shows the top view and Fig. $4 \mathrm{~h}$ and i depict the side views of scaffold \#14 prepared using the 3DP/ TIPS method ( $10 \% \mathrm{nHA})$. The PLGA concentration of $10 \%$ is identical for this scaffold and scaffold \#2 (Fig. 4d-f). The same microscale structural features are visible in scaffold \#14. The top view in Fig. $4 \mathrm{~g}$ shows the presence of some undissolved PEG, which was unintended but could potentially be beneficial for cell adhesion. Figure $4 j$ and $\mathrm{k}$ show the side views and Fig. $4 \mathrm{l}$ shows the top view of scaffold \#14 after 2 weeks of culture inside the bioreactor. These images show evidence of cell adhesion to the surface of PLGA/nHA scaffold, including the submicron surface topography that allows cells to bind (Fig. 4l). 

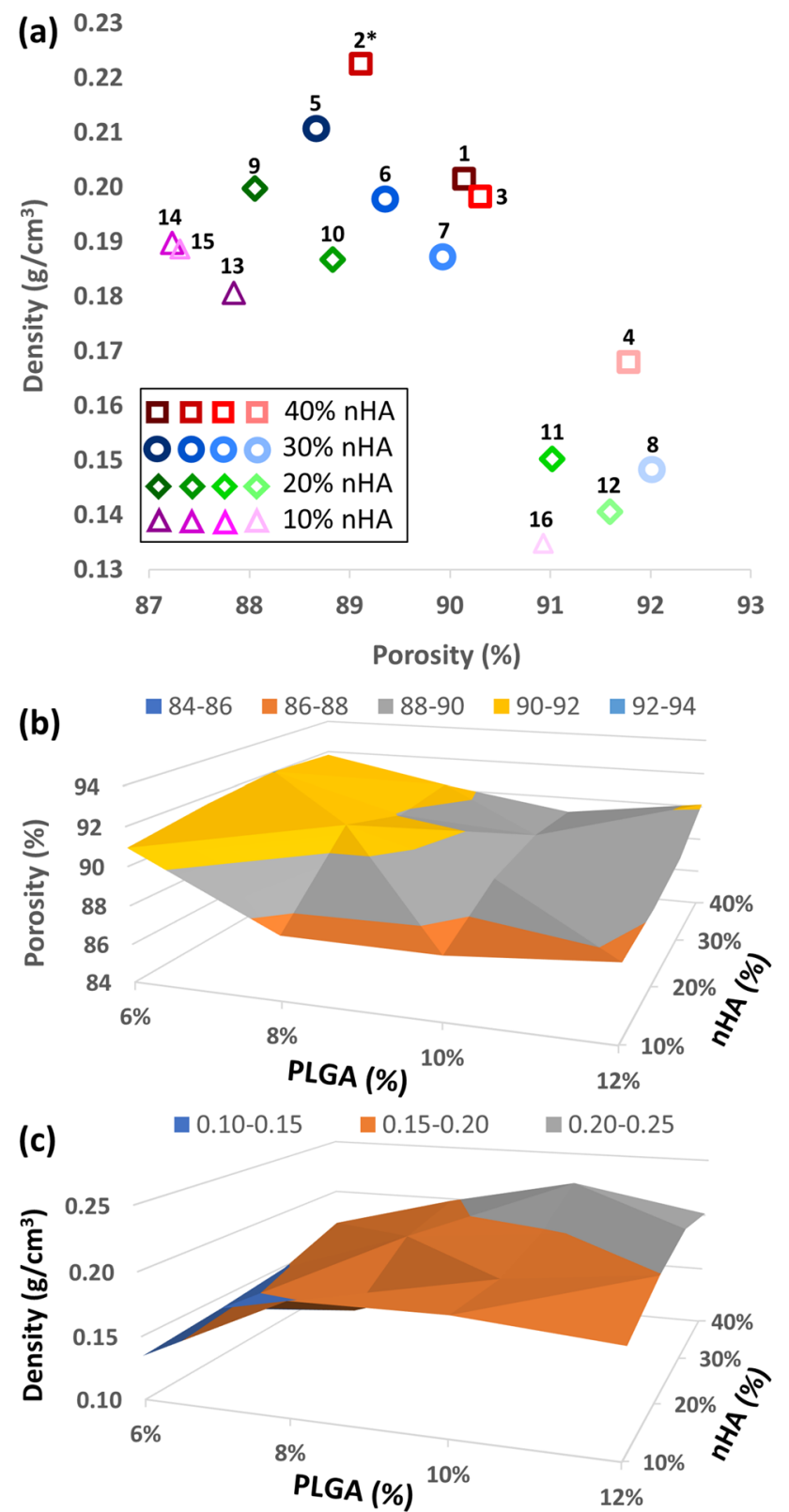

Fig. 3 a Density vs. porosity for the 16 scaffolds listed in Table 1 . The set of scaffolds containing $40 \%, 30 \%, 20 \%$, and $10 \% \mathrm{nHA}$ have been identified in the image. The darker the color of the symbols, the higher the PLGA concentration (i.e., $12 \%, 10 \%, 8 \%$, and $6 \%$ ). $\left(^{*}\right.$ ) The density and porosity of scaffold \#2 was averaged over 2 samples, whereas the remaining scaffolds were averaged over 3 samples $(1,3,4$, and 5$)$ or 4 samples (6-16); b \& $\mathbf{c}$ The 3D surface plots of scaffold porosities and densities versus $\mathrm{nHA}$ content and PLGA concentration

Figure $4 \mathrm{~m}$-o show the top views of CellCeram ${ }^{\mathrm{Tm}}$ scaffold after 2 weeks of culture inside the bioreactor, with evidence of cell adhesion to the surface of the scaffold. Figure $4 \mathrm{~m}$ indicates that the pores in the CellCeram ${ }^{\mathrm{m}}{ }^{\text {scaffold }}$ have some level of interconnectivity, but also reveals very small pores at the sites connecting the channels. Figure
S1 under Supplementary Material shows some additional SEM images of the scaffolds investigated in this study.

\subsection{The effect of $\mathrm{nHA}$ loading on the scaffold density}

Microcomputed tomography $(\mu \mathrm{CT})$ is a method of nondestructive imaging extensively used in research on tissue-engineering. Figure 5 shows $\mu C T$ images of the scaffold architecture for the TIPS-only PLGA/nHA scaffold (Fig. 5a), cell-free 3DP/TIPS PLGA/nHA scaffold \#2, \#6, and \#14 (Fig. 5b-d), as well as cell-seeded scaffold \#14 and CellCeram $^{\text {mm }}$ scaffold (Fig. 5e-h). The top views of scaffold $\# 2$, scaffold \#6, and scaffold \#14 clearly show the network of macrochannels generated by sacrificial PEG templates. As for the cell-seeded scaffolds, Fig. 5e and f show the top and side views of scaffold \#14 after two weeks of culture inside the bioreactor. The scaffold appears to retain its structural integrity after being subjected to fluid flow for two weeks. The corresponding $\mu \mathrm{CT}$ images in Fig. $5 \mathrm{~g}$ and $\mathrm{h}$ for the CellCeram ${ }^{\text {tm }}$ scaffold show no signs of disintegration after two weeks of fluid flow inside the bioreactor.

Figure $5 i$ shows the distribution $\%$ of the density in Hounsfield Units (HU) throughout cell-free scaffold \#2 and scaffold \#6, respectively, where higher values of $\mathrm{HU}$ on the $x$ axis represent higher densities. Scaffold \#2 containing $40 \% \mathrm{nHA}$ is expected to have a higher density (Fig. 3), which is also evidenced by its higher distribution $\%$ at greater $\mathrm{HU}$ values. The sharper peak for scaffold \#6 containing $30 \% \mathrm{nHA}$ at smaller $\mathrm{HU}$ values $(\sim-1000 \mathrm{HU})$ appears to indicate more pores occupied by air. Figure $5 \mathrm{j}$ shows the $\mu \mathrm{CT}$ images of scaffold \#14 without cells and after 2 weeks of culture inside the bioreactor. Again, the sharper peak for the scaffold exposed to fluid flow might indicate the washout of left-over PEG in the structure. The images in Fig. $5 \mathrm{k}$ for the CellCeram ${ }^{\text {tm }}$ scaffold show a small shift of the peak towards higher HU values, although it may not be directly linked to bone growth after 2 weeks of culture. It should be noted that polymers are usually identified between -590 and $-370 \mathrm{HU}$, whereas bone and $\mathrm{HA}$ are often characterized with values exceeding - $17 \mathrm{HU}$ [27].

\subsection{Simulation of fluid flow inside the perfusion bioreactor}

Figure 6a shows the geometry of the simple cylindrical model used to determine the appropriate mesh size (Fig. 6b). The simulation of the velocity profile for this model is presented in Fig. $6 \mathrm{c}$. The element size chosen for the mesh in COMSOL was "finer", which resulted in 1762 elements in the cross-sectional area of the cylinder. In Fig. $6 \mathrm{~d}$, the graph of shear rate vs. arc length using the 


Scaffold:
TIPS-only (b8c)
PLGA: $10 \%$
nHA: $10 \%$
Scaffold 2:
3DP/TIPS
PLGA: 10\%
nHA: $40 \%$
Scaffold 14:
3DP/TIPS
PLGA: 10\%
nHA: 10\%
Scaffold 14:
3DP/TIPS
PLGA: 10\%
nHA: 10\%
Bioreactor
(2 weeks)
Scaffold:
CellCeram ${ }^{\text {TM }}$
Bioreactor
(2 weeks)
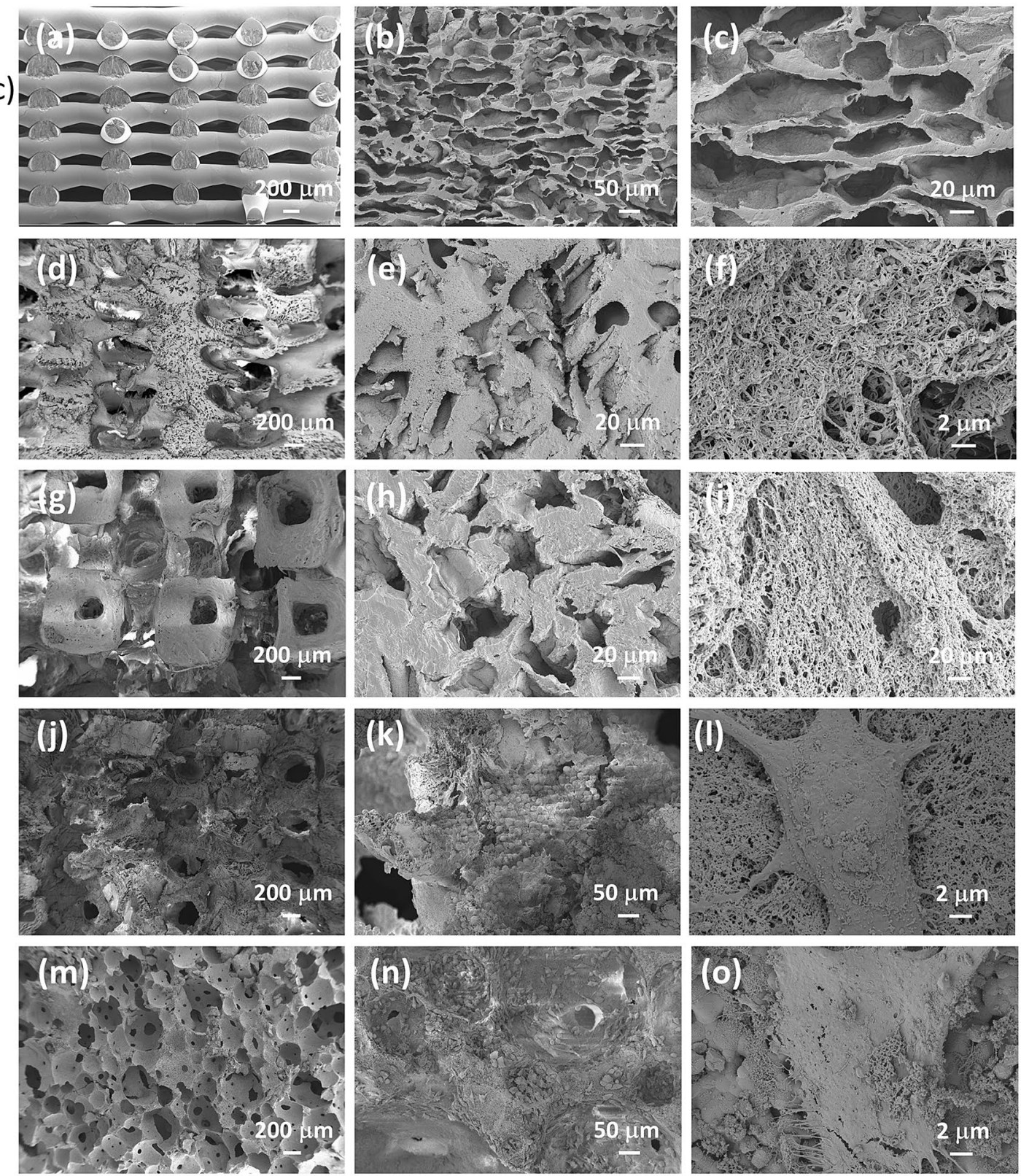

Fig. 4 SEM images showing a the side view of a PEG template, $\mathbf{b}$ \& c the side views of a PLGA/nHA scaffold prepared using the TIPSonly method (provided for comparison), $\mathbf{d}-\mathbf{f}$ the side views of scaffold \#2 prepared using the 3DP/TIPS method, $\mathbf{g}$ the top view and

Newtonian fluid model indicates that the "finer" mesh discretization yielded a fairly smooth overall shear rate profile ${ }^{1}$ with a wall shear rate of $4.51 \mathrm{~s}^{-1}$.

Further simulations were performed using meshes with more elements, but these simulations also resulted in a wall shear rate of approximately $4.5 \mathrm{~s}^{-1}$. Figure $6 \mathrm{e}$ compares the shear stress values calculated using Eq. 7 with the simulated ones using the simple cylindrical model. h $\& \mathbf{i}$ the side views of scaffold \#14 prepared using the 3DP/TIPS method, $\mathbf{j} \& \mathbf{k}$ the side views and I the top view of scaffold \#14 after 2 weeks of culture inside the bioreactor, and $\mathbf{m}$-o the top views of CellCeram ${ }^{\text {mm }}$ scaffold after 2 weeks of culture inside the bioreactor

Based on these results, it was concluded that the small differences in wall shear rate values were negligible compared to the extensive computational times required to run the "extra fine" mesh size in COMSOL, and thus the "finer" mesh discretization was selected for further computational analyses. The use of this mesh also enabled a similar number of elements to be used in the cross section of each cylinder in the half-scaffold model. 

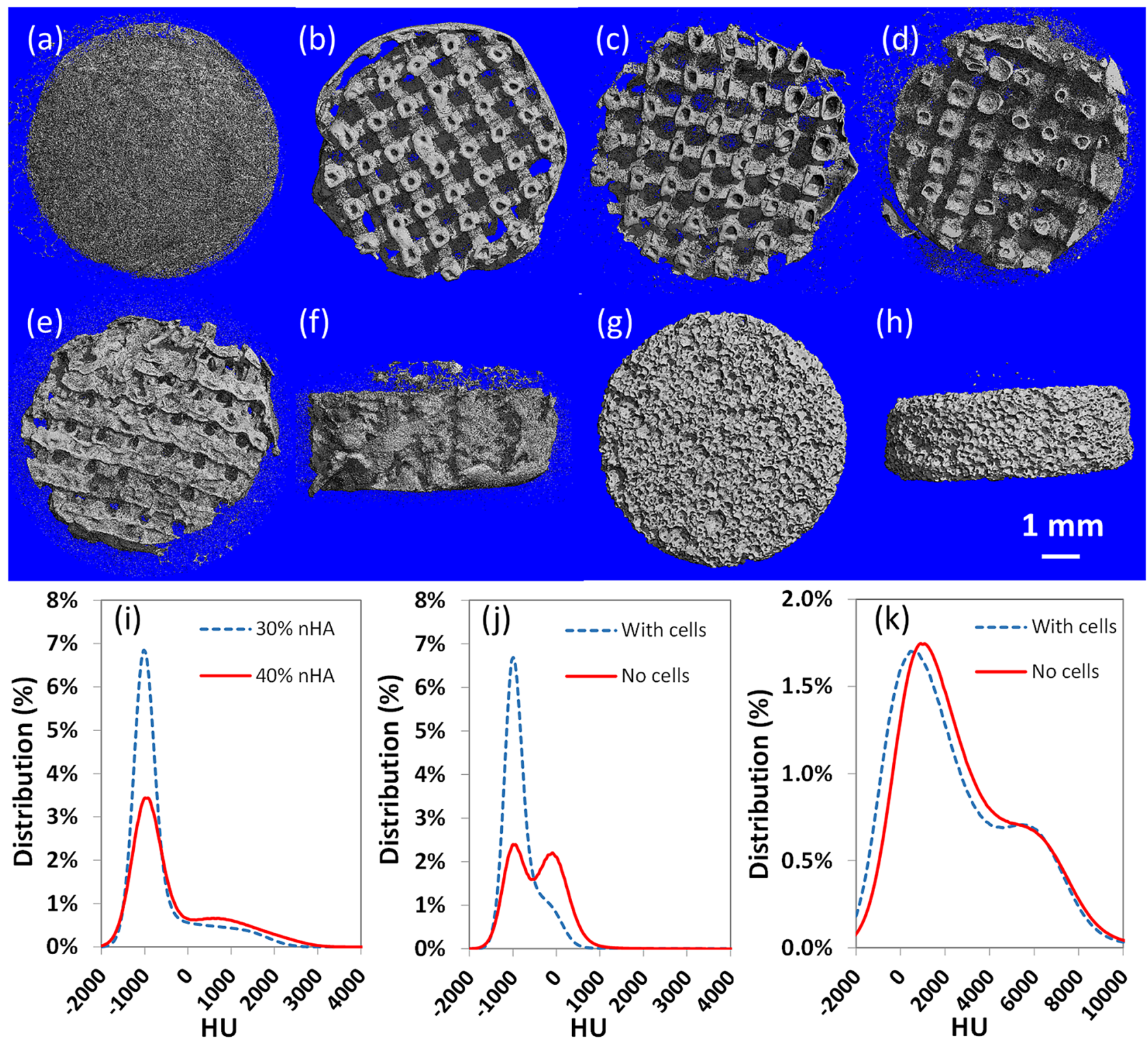

Fig. 5 The $\mu C T$ images showing a the top view of a PLGA/nHA scaffold prepared using the TIPS-only method (provided for comparison), b-d the top views of scaffold \#2, scaffold \#6, and scaffold \#14, respectively, e \& $\mathbf{f}$ the top and side views of scaffold \#14 after two weeks of culture inside the bioreactor, $(g \& h)$ the top and side views of CellCeram ${ }^{\text {mm }}$ scaffold after two weeks of culture inside

The cylindrical model was scaled up to represent one half of the physical scaffold featuring 38 inlet channels, each with a diameter of $400 \mu \mathrm{m}$, oriented within a half-cylinder 4-mm-high and 10-mm-diameter. Figure 7a depicts the half-scaffold model that was used to determine the optimal perfusion flow rate. A 4-point-probe analysis was established in the scaffold, two at the inlet channels and the other two at the outlet channels. The purpose of these probes was to track the shear stress at those points as the inlet flow rate was varied. Various flow rates of the culture the bioreactor. $\mathbf{i}-\mathbf{k}$ The distribution $\%$ of the density in Hounsfield units (HU) throughout (i) scaffold \#2 and scaffold \#6, j scaffold \#14 without cells and after 2 weeks of culture inside the bioreactor, and k CellCeram ${ }^{\text {rm }}$ scaffold without cells and after 2 weeks of culture inside the bioreactor

media through the scaffold were simulated, and the wall shear stress $\left(\tau_{w}\right)$ was tracked until a flow rate that yielded between 9-26 mPa shear stress at the outlet point was obtained.

Figure $7 \mathrm{~b}$ shows the velocity magnitudes for a simulation using a volumetric flow rate of $8.0 \times 10^{-9} \mathrm{~m}^{3} / \mathrm{s}$ imposed at the inlet to each cylinder. The shear rate throughout the half-scaffold model is shown in Fig. 7c, which yielded a wall shear rate of $\sim 26 \mathrm{~s}^{-1}$ at the probe location ( $\tau_{w} \approx 26 \mathrm{mPa}$ ). Figure $7 \mathrm{~d}$ shows the simulated 
(a)
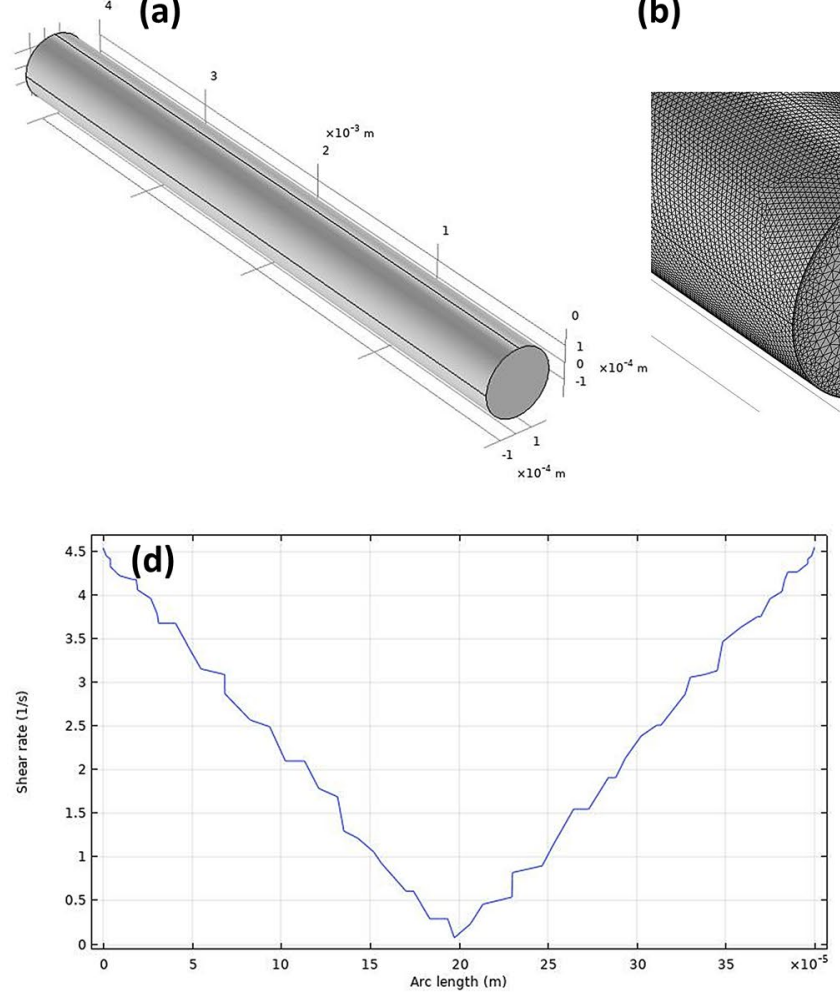

Fig. 6 a The cylindrical model used for finding the appropriate mesh size for the simulations, $\mathbf{b}$ the "finer" mesh size used for the simulations, $\mathbf{c}$ the velocity profile throughout the cylindrical model, d the graph of shear rate vs. arc length for the same geometry

shear rates using a volumetric flow rate of $2.67 \times 10^{-9}$ $\mathrm{m}^{3} / \mathrm{s}$ imposed at the inlet to each cylinder. This flow rate yielded a wall shear rate of $\sim 9 \mathrm{~s}^{-1}$ at the probe location $\left(\tau_{w} \approx 9 \mathrm{mPa}\right)$, leading to an overall inlet mass flow rate of $\sim 0.1 \mathrm{~g} / \mathrm{s}$ for the half scaffold (38 cylinders) and $\sim 0.2 \mathrm{~g} / \mathrm{s}$ for the whole scaffold. We used this flow rate for the peristaltic pump of the perfusion bioreactor (i.e., $40 \mathrm{rpm}$ ), given the fact that the microporous structure and surface roughness of the 3DP/TIPS scaffolds were disregarded in the simulations. Hence, this flow rate was assumed to be a reasonable approximation to attain a wall shear stress approaching $20 \mathrm{mPa}$.

\subsection{DNA content assay}

DNA content assays were performed on $1 / 2$ scaffolds, and therefore, it was assumed that the initial number of cells present was $1.5 \times 10^{6}$ when seeding the scaffolds. The mean number of adhered cells on day 0 was $1.36 \times 10^{5}$ for scaffold \#14 and $2.37 \times 10^{5}$ for the CellCeram ${ }^{\text {rm }}$ scaffold. Hence, the percentage of cells adhered on day 0 were $9.04 \% \pm 5.1 \%$ and $15.8 \% \pm 2.5 \%$, respectively. Figure $8 \mathrm{a}$ shows the number of cells for the CellCeram ${ }^{\text {tm }}$ scaffold and (c)
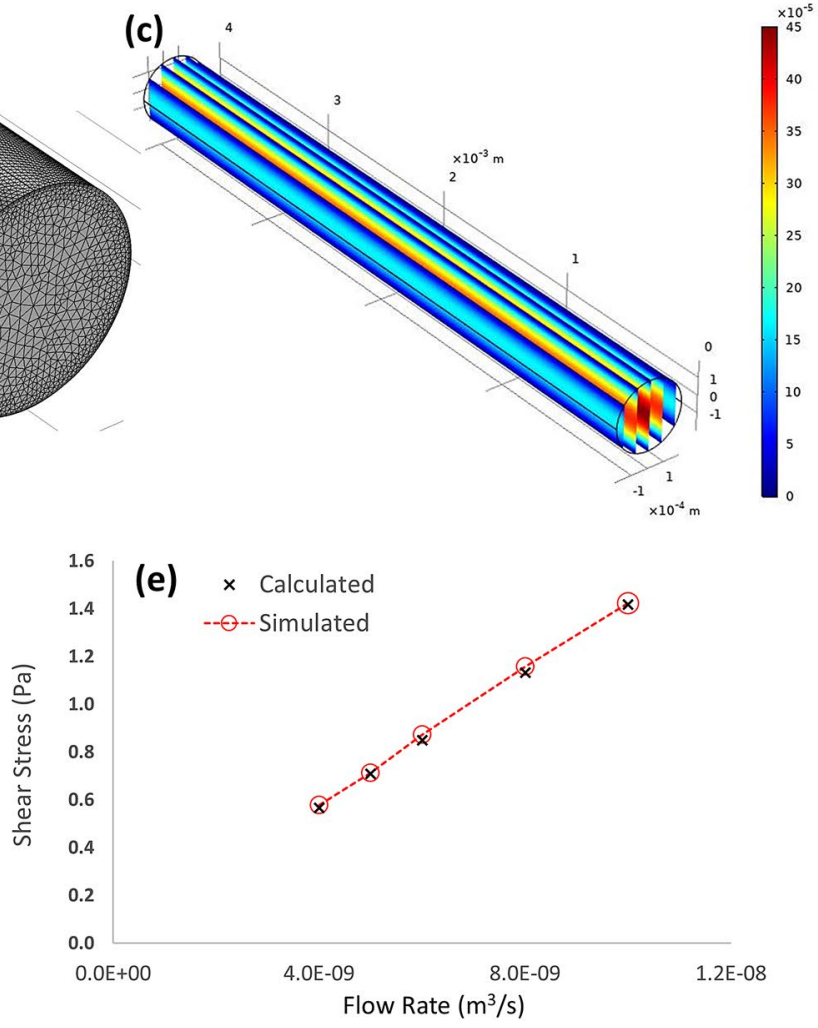

using the Newtonian fluid model, and e the wall shear-stress values calculated using Eq. 7 compared to the simulated ones using the cylindrical model

for scaffold \#14 on day 0 , and after 14 days of cell culture in a tissue-culture dish (static) and inside the bioreactor (dynamic). For scaffold \#14, the results have been presented for two bioreactor chambers denoted as chamber $A$ and chamber B in Fig. 8a. These independent scaffolds were cultured in separate bioreactor chambers under the same fluid flow conditions predicted by COMSOL.

Under static cell culture, scaffold \#14 showed no statistically-significant difference in the number of cells present on day 0 and day 14 , whereas the corresponding results for the CellCeram ${ }^{\text {tm }}$ scaffold was statistically significant. When the two scaffold types were compared at the same time point, scaffold \#14 and the CellCeram ${ }^{\mathrm{Tm}}$ scaffold showed statistically-significant differences on day 0 as well as on day \#14.

Under dynamic cell culture inside the bioreactor, the CellCeram ${ }^{\text {'m }}$ scaffold showed no statistically-significant difference in the number of cells present on day 0 and after 14 days of culture inside the bioreactor. As for scaffold \#14, a statistically-significant difference was observed between the number of cells present on day 0 and after 14 days of culture inside chamber $A$, but no difference between the number of cells present on day 0 and after 14 days 


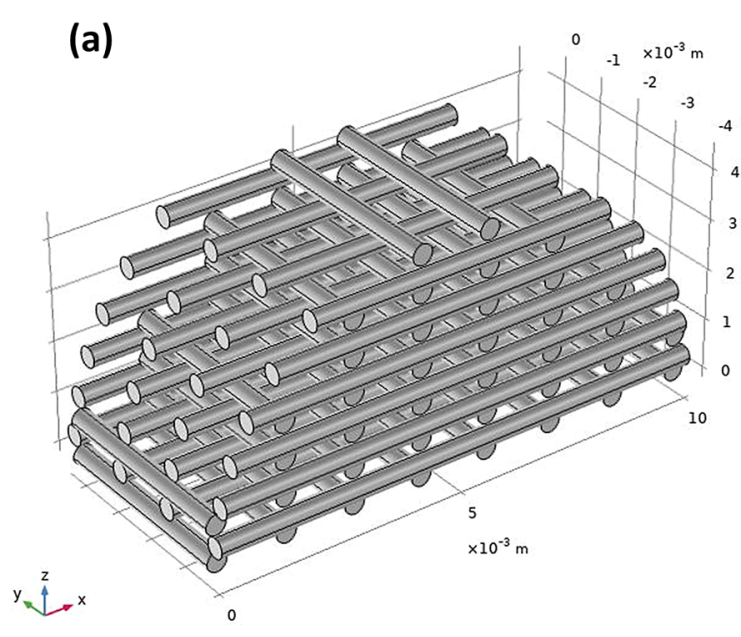

(c)

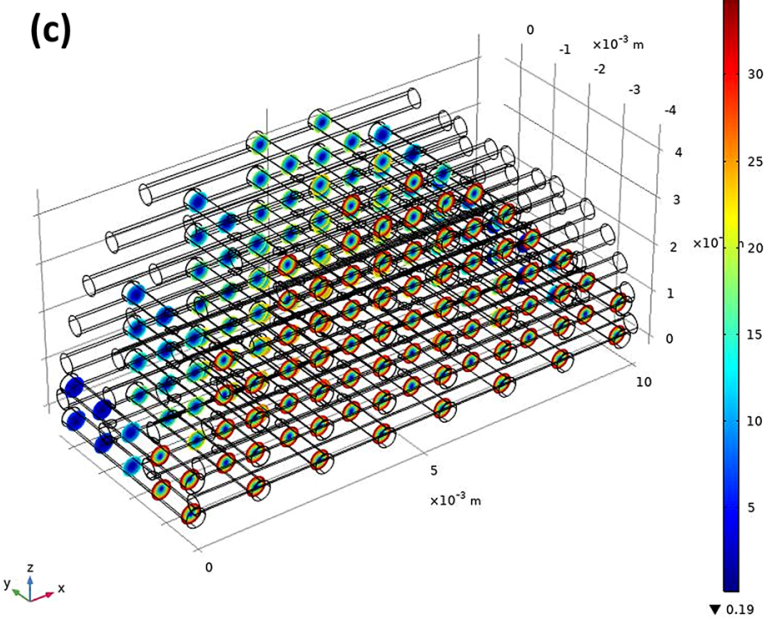

Fig. 7 a The 3D model of the half-scaffold used for the simulation of fluid flow inside the perfusion bioreactor, $\mathbf{b}$ the velocity magnitudes throughout the 3D model for a volumetric flow rate of $8.0 \times 10^{-9} \mathrm{~m}^{3} / \mathrm{s}$ at the inlet to each cylinder, $c$ the

of culture inside chamber B. When the two scaffold types were compared on day 14, the number of cells present was not significantly different between the CellCeram ${ }^{\text {tm }}$ scaffold and scaffold \#14 in chamber A. Nevertheless, the CellCeram ${ }^{\text {tm }}$ scaffold showed significantly higher number of cells compared to scaffold \#14 in chamber B.

The normalized cell proliferation was calculated by dividing the number of cells by the cell retention on day 0 for each scaffold. Figure $8 \mathrm{~b}$ shows the normalized number of cells for both scaffold types cultured under static and dynamic conditions. For the most part, the results in Fig. $8 \mathrm{~b}$ are comparable to the ones presented in Fig. $8 \mathrm{a}$, except for the scaffold cultured in chamber A of the bioreactor. The normalized number of cells for scaffold 14 in chamber A was more than twofold that of CellCeram ${ }^{\text {tm }}$ scaffold, both cultured inside the bioreactor for 14 days (b)
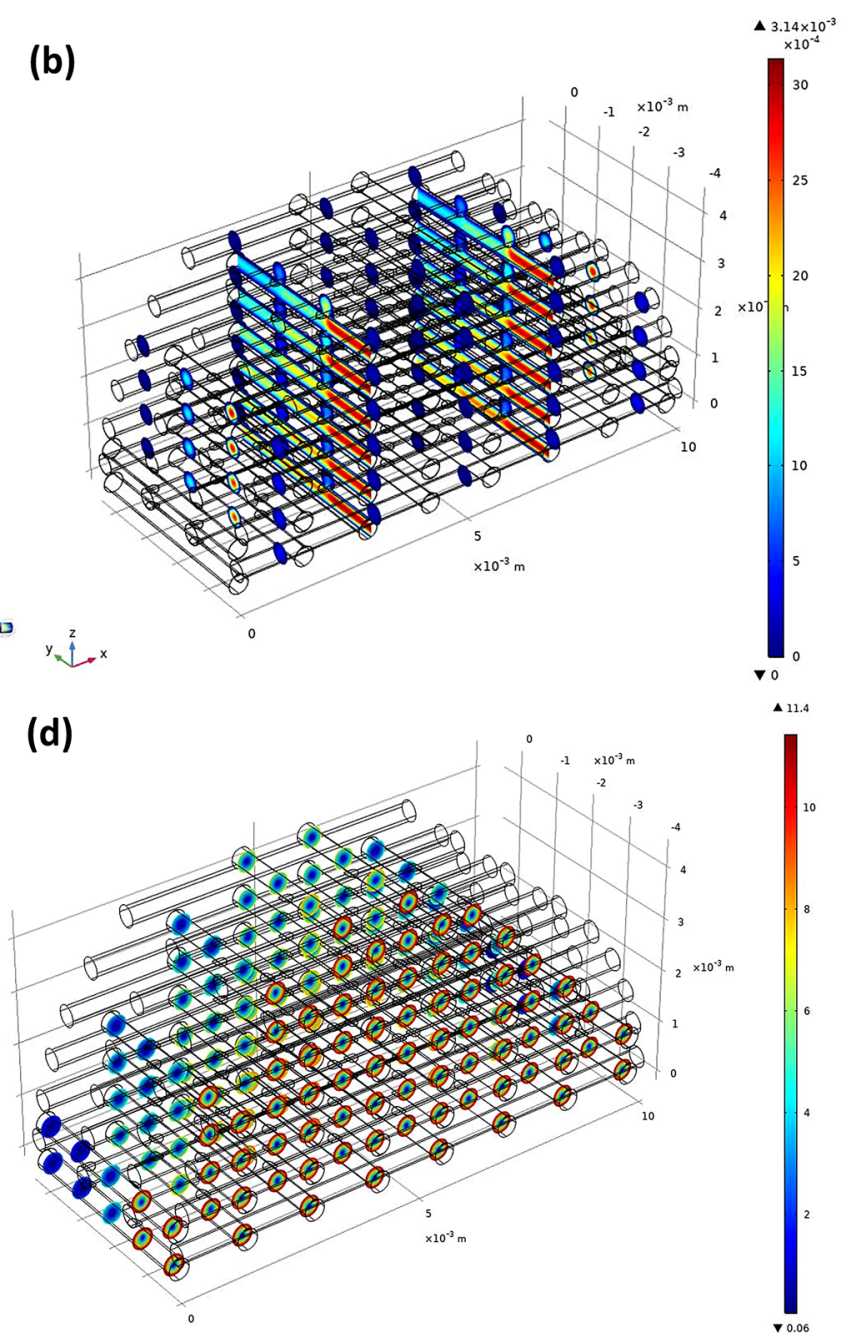

shear rate throughout the 3D model for a volumetric flow rate of $8.0 \times 10^{-9} \mathrm{~m}^{3} / \mathrm{s}$ at the inlet to each cylinder, $\mathbf{d}$ the shear rate throughout the $3 \mathrm{D}$ model for a volumetric flow rate of $2.67 \times 10^{-9} \mathrm{~m}^{3} / \mathrm{s}$ at the inlet to each cylinder

$(p<0.05)$. Substantial variability between scaffold \#14 cultured in chamber $A$ and $B$ indicate the need for further investigation of cell retention and proliferation on 3DP/ TIPS scaffolds. Nevertheless, the significant improvement in cell proliferation upon culture inside the perfusion bioreactor (vs. static culture) demonstrates the role of microchannels in making these 3DP/TIPS scaffolds a promising candidate for scaffold-based tissue engineering.

\section{Discussion}

Due to the high metabolic activity of bone cells, the size of 3D scaffold-tissue constructs that can be used in bone tissue engineering is very limited [25]. Using a combination of the TIPS and 3DP techniques allowed us to create 


\subsection{E+06 $\square$ CellCeram $^{\circledR} \square$ Scaffold \#14}
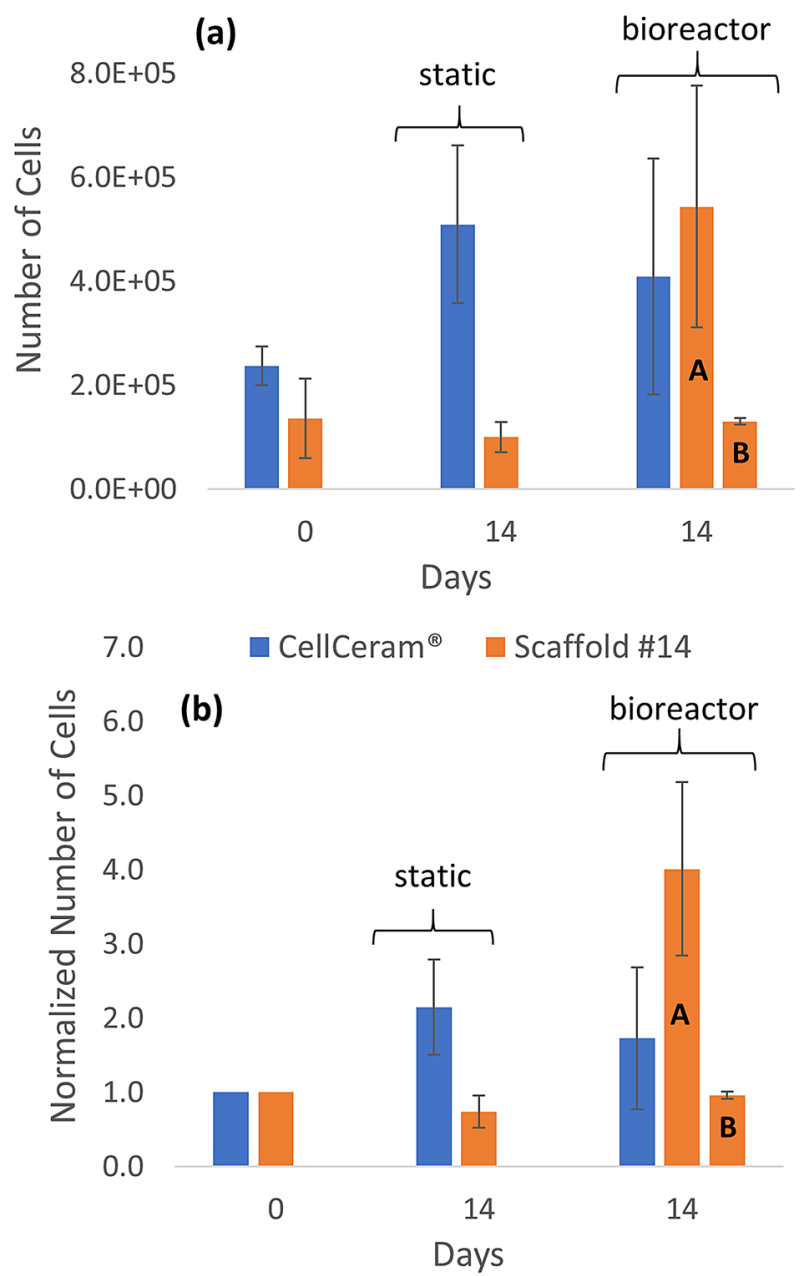

Fig. 8 a Number of cells for the CellCeram ${ }^{\text {Th }}$ scaffold and for scaffold \#14 on day 0 , and after 14 days of cell culture in a tissue-culture dish (static) and inside the bioreactor. For scaffold \#14, the results have been presented for two bioreactor chambers $(n=3)$. b The corresponding number of cells normalized with respect to cell adhesion on day 0

scaffolds with a hierarchical structure. These scaffolds were highly porous, with a porosity of $>85 \%$, and contained both macrochannels and micropores. Previous studies have shown that a pore size exceeding $350 \mu \mathrm{m}$ enhances cell migration and angiogenesis [28]. Pore interconnectivity is very important to guide bone growth and create a template for formation of new bone. The SEM and $\mu \mathrm{CT}$ images of the 3DP/TIPS scaffolds revealed the presence of macrochannels, with diameters exceeding $300 \mu$ m (Figs. 4 and 5).

Orthogonally-interconnected architectures have been reported to improve mass transport, while helping to guide bone ingrowth $[29,30]$. The high percentage of $\mathrm{nHA}(40 \%)$ did not interfere with the formation of macrochannels (Fig. 4d). This could be an advantage of our scaffolds over CellCeram ${ }^{\text {Tm }}$ scaffolds. Combined with micropores and sub-micron structural features produced by TIPS, as well as the nanoscale features of our scaffolds in the presence of $\mathrm{nHA}$, it is hypothesized that these scaffolds could support osteogenic differentiation, bone ingrowth, and vascularization in vivo. Cells were visible across the 3DP/TIPS scaffolds, particularly in Fig. 4 l showing cell spreading on the sub-micron structure of the scaffold. The surface topography of these micropores allows for cell attachment [31] and can influence cell morphology. The pores appeared to be relatively interconnected as seen by SEM. This is consistent with other studies that have reported on PLGA scaffolds prepared by the TIPS process $[32,33]$. Figure $5 e$ and $f$, showing the $\mu C T$ images of scaffold \#14 after two weeks of culture inside the bioreactor, indicated that the scaffold retained its integrity after being subjected to fluid flow for two weeks. Future cell culture inside the bioreactor for 3-6 weeks could shed light on the significance of these findings.

Compared to our previous studies [22, 23], this study included a longer TIPS quenching time in the environmental chamber and a longer washing time in a water bath to remove the embedded PEG template. In this study, the porosities of the scaffolds were comparable to those reported in our previous study for scaffolds containing $0 \%$, $10 \%$, and $20 \% \mathrm{nHA}$ and $10 \%$ PLGA. Loading the scaffolds with $30 \%$ or $40 \% \mathrm{nHA}$ and changing the PLGA concentration between 6 and $12 \%$ did not deteriorate the porosity of the 3DP/TIPS scaffolds in this study (Fig. 3a and b). Hence, these results enabled us to delineate the role of higher $\mathrm{nHA}$ content and PLGA concentration on the porosity and density of 3DP/TIPS scaffolds. Figure $3 a$ and $c$ indicated a correlation between the density of the scaffolds and their $\mathrm{nHA}$ content, which is anticipated due to the difference in the densities of PLGA and $\mathrm{nHA}$. A similar correlation existed between the $\mathrm{nHA}$ content and the porosity of the scaffolds. The higher the nHA content, the higher was the porosity, whereas increasing the PLGA concentration reduced the porosity of the scaffolds (Fig. $3 a$ and b). It is desirable to generate moderate-to-high porosities without compromising the mechanical properties of the scaffolds. Scaffold \#14 had the lowest porosity in this study $(87 \%$ in Fig. 3a), yet high enough to serve as a tissue engineering scaffold, and had the optimal composition and macrochannel diameter as reported in our previous study [22].

The purpose of simulating the shear stress on the wall of a cylinder was to develop a better understanding of the fluid flow through the scaffold architecture, to estimate the wall shear stress $\left(\tau_{w}\right)$, and to approach $\tau_{w} \approx 20 \mathrm{mPa}$ as reported by others [25]. The simulations gave a reasonable estimate of the shear stress the cells on the interior of the scaffold would experience, and could potentially 
enhance the differentiation of the cells based on the shear stress to which they are subjected. Mechanical forces can be detected by cell surface receptors known as integrins. It has been hypothesized that integrins act as a conduit for transducing physical forces into chemical responses within the cell [34]. It is important to note that the surface topography and elasticity of the scaffold may influence cell differentiation by the same mechanism [35]. As a limitation of this study, the simulations assumed that the macrochannels generated by PEG removal were perfectly cylindrical and symmetrical, though this is likely not the case due to effects of gravity on the polymer melt during the 3D-plotting process. In addition, the microporous structure and surface roughness of the 3DP/TIPS scaffolds were disregarded in the simulations. Hence, our future studies will take this into consideration and look into the effect of fluid flow and mass diffusion throughout the microporous matrix produced by the TIPS process. Furthermore, this investigation could allow optimizing the spatial distribution of cells throughout our hierarchical 3D scaffold and potentially improve cell migration, proliferation, and differentiation.

The results of our DNA assays indicated that the difference in cell proliferation between the CellCeram ${ }^{\mathrm{Tm}}$ scaffold and the PLGA/nHA scaffold (scaffold \#14) was not statistically significant $(p>0.05)$ after 14 days in a perfusion bioreactor. However, while the number of cells between day 0 and day 14 did not significantly change for the CellCeram ${ }^{\mathrm{mm}}$ scaffold, a statistically-significant difference was observed between day 0 and day 14 for the scaffold \#14 in bioreactor chamber A. In addition, the normalized number of cells for the scaffold \#14 cultured in bioreactor chamber A was more than twofold that of CellCeram ${ }^{\mathrm{Tm}}$ scaffold $(p<0.05)$. Further investigation with a higher number of scaffolds in each series will help to draw a more robust conclusion on the efficiency of the perfusion bioreactor used in this study.

Overall, the results of DNA assay are evidence that both scaffold types can support cell attachment. In static culture, the CellCeram ${ }^{\text {tm }}$ scaffold showed an ability to support cell proliferation, as evidenced by the significantly higher number of cells on day 14 when compared to the number on day 0 . The PLGA/nHA scaffold (scaffold \#14) that was cultured under static conditions showed no evidence of cell proliferation, though it did show a capability to sustain a cell colony, as the number of cells did not significantly change between day 0 and day 14 . Despite all of the scaffolds being seeded with the same number of cells and being grown in the same conditions, we saw substantial variability in cell attachment on both CellCeram ${ }^{\mathrm{m}}$ and PLGA/nHA scaffolds.

Previous studies have reported on the hydrophobicity of PLGA scaffolds and its adverse effect on cell adhesion and growth [36, 37]. Lao et al. have reported $22.5 \%$ of cell adhesion after $24 \mathrm{~h}$ on electrospun scaffolds made of $\mathrm{nHA}$ and PLGA, with similar results for electrospun PLGA scaffolds [37]. A lower cell adhesion was observed in our study $(9.04 \% \pm 5.1 \%)$. Reducing the variability in cell loading onto our scaffolds will be pursued in our future study to improve the cells retained on day 0 . Furthermore, our ongoing work is making use of gas plasma treatment to reduce the hydrophobicity of the dominant PLGA in our PLGA/nHA scaffolds in order to improve cell adhesion [38]. It should be noted that the sub-micron-size surface topography (Fig. 4f) has the potential of enhancing cell adhesion. This has been reported by others, indicating that the TIPS method is capable of generating nanotextures and could yield a surface roughness favoring cell attachment and protein adsorption [31].

Porous $\beta$-TCP/HA scaffolds similar to CellCeram ${ }^{\text {Tm }}$ have a proven ability to support cell attachment and proliferation both in vivo [39] and in vitro [40]. Moreover, PLGA/nHA composite scaffolds have also shown an ability to support cell attachment and proliferation in vitro $[22,41]$ and cell infiltration in vivo [19]. Further investigation of these scaffolds will be necessary to determine if they can support cell proliferation as well as cell attachment in a perfusion bioreactor for an extended period of time. In order to determine whether or not PLGA/nHA composite scaffolds can promote MC3T3-E1 differentiation in dynamic culture conditions, it will be necessary to conduct trials longer than the 14 days used in our experiments. In our future work, we will extend this study to longer time points and make use of assays that measure osteoblast differentiation and mineralization.

Our ultimate goal is to implant a set of our optimal scaffolds in vivo and investigate bone formation in animal models. The $\mu \mathrm{CT}$ analysis of the implanted constructs will enable us to evaluate bone growth via quantifying trabecular thickness (Tb.Th), which is defined as the diameter of the largest sphere that can fit within the structure being analyzed [42]. Furthermore, the changes in the trabecular spacing (Th.Sp) can be attributed to cell growth inside the scaffold pores over time. We anticipate that these future studies will help to evaluate the suitability of our scaffolds for in vivo implantation.

\section{Conclusions}

Many previous studies have shown that porous scaffolds are a promising treatment option for bone nonunion, but further investigation of their properties is required. This paper reports differences in porosity and density based on varying the percentage of polymer and ceramic components in PLGA/nHA scaffolds. 
Sixteen PLGA/nHA scaffolds were produced according to a full factorial design of experiments with four levels across two factors. These scaffolds showed high porosities ( $>85 \%)$ and a hierarchical structure featuring macrochannels $(>350 \mu \mathrm{m})$ and micropores $(<100 \mu \mathrm{m})$. In order to better understand the shear forces experienced by cells in the interior structure of the scaffold, a model was created in COMSOL and subjected to laminar flow. The results of our cell culture experiment indicated that scaffold \#14, our "optimal" scaffold, was capable of supporting MC3T3-E1 attachment in a dynamic culture environment over 14 days at a level similar to that of commercial CellCeram ${ }^{\text {tm }}$ scaffolds. This was supported by the SEM images of both the PLGA/nHA and CellCeram ${ }^{\text {mm }}$ scaffolds, which appear to show cells adhered to the surface of both scaffold types. The significant improvement in cell proliferation upon culture inside the perfusion bioreactor (vs. static culture) demonstrated the role of macrochannels in making the 3DP/TIPS scaffolds a promising candidate for scaffold-based tissue engineering. Reducing the variability in cell loading onto these scaffolds will be pursued in our future studies to improve the cells retained on day 0 . Furthermore, performing further in vitro testing with scaffold formulations beyond our optimal scaffold would be helpful for better understanding the relationship between the scaffold composition, cell adhesion, proliferation, and differentiation. After further evaluation of these scaffolds under dynamic cell culture conditions, an optimal scaffold could be chosen for in vivo testing in animal models.

Acknowledgements Research reported in this paper was supported by the National Institute of Arthritis and Musculoskeletal and Skin Diseases of the National Institutes of Health under Award Number 1R15AR066269-01A1 (AMY/PFJ). The content is solely the responsibility of the authors and does not necessarily represent the official views of the National Institutes of Health. In addition, AMY acknowledges the funds from the Ohio Board of Regents, the Ohio Third Frontier Program, and Miami University Committee on Faculty Research. We would like to thank Michelle Lynch from University of Michigan for $\mu C T$ imaging, Dr. Jing Zhang, Junyi Liu, Catherine Wood, and Douglas Hart for their technical contributions, as well as Laurie Edwards for her administrative assistance.

Authors' contributions KS and SK researched literature, prepared the scaffolds, and performed the static and dynamic cell culture under the supervision of AMY and PFJ. CG was involved in cell culture and biological assays, AV, AS, AS, and RG developed the scaffold geometries in COMSOL and performed the initial COMSOL simulations (under the guidance of JM and AMY), MD performed all the SEM imaging, KS finalized the COMSOL simulations and wrote the first draft of the manuscript. All authors reviewed and edited the manuscript and approved the final version of the manuscript.

Funding Research reported in this paper was supported by the National Institute of Arthritis and Musculoskeletal and Skin Diseases of the National Institutes of Health under Award Number 1R15AR066269-01A1 (AMY/PFJ). The content is solely the responsibility of the authors and does not necessarily represent the official views of the National Institutes of Health. In addition, AMY acknowledges the funds from the Ohio Board of Regents, the Ohio Third Frontier Program, and Miami University Committee on Faculty Research.

\section{Declarations}

Conflict of interest The authors declare that there are no conflicts of interest or competing interests.

Open Access This article is licensed under a Creative Commons Attribution 4.0 International License, which permits use, sharing, adaptation, distribution and reproduction in any medium or format, as long as you give appropriate credit to the original author(s) and the source, provide a link to the Creative Commons licence, and indicate if changes were made. The images or other third party material in this article are included in the article's Creative Commons licence, unless indicated otherwise in a credit line to the material. If material is not included in the article's Creative Commons licence and your intended use is not permitted by statutory regulation or exceeds the permitted use, you will need to obtain permission directly from the copyright holder. To view a copy of this licence, visit http://creativecommons. org/licenses/by/4.0/.

\section{References}

1. Boonen S, Dejaeger E, Vanderschueren D et al (2008) Osteoporosis and osteoporotic fracture occurrence and prevention in the elderly: a geriatric perspective. Best Pract Res Clin Endocrinol Metab 22:765-785

2. Jiao H, Xiao E, Graves DT (2015) Diabetes and its effect on bone and fracture healing. Curr Osteoporos Rep 13:327-335

3. Sen MK, Miclau T (2007) Autologous iliac crest bone graft: should it still be the gold standard for treating nonunions? Injury 38:2-7

4. Thomas JD, Kehoe JL (2020) Bone nonunion. StatPearls Publishing, Treasure Island

5. Loh QL, Choong C, Oxon D et al (2013) Three-dimensional scaffolds for tissue engineering applications: role of porosity and pore size. Tissue Eng Part B Rev 19:1-18

6. Sheikh Z, Najeeb S, Khurshid Z et al (2015) Biodegradable materials for bone repair and tissue engineering applications. Materials (Basel) 8:5744-5794

7. Gentile P, Chiono V, Carmagnola I et al (2014) An overview of poly(lactic-co-glycolic) Acid (PLGA)-based biomaterials for bone tissue engineering. Int J Mol Sci 15:3640

8. Vats A, Tolley NS, Polak JM et al (2003) Scaffolds and biomaterials for tissue engineering: a review of clinical applications. Clin Otolaryngol Allied Sci 28:165-172

9. Bracey DN, Seyler TM, Jinnah AH et al (2018) A decellularized porcine xenograft-derived bone scaffold for clinical use as a bone graft substitute: a critical evaluation of processing and structure. J Funct Biomater 9:1-17

10. Mittwede PN, Gottardi R, Alexander PG et al (2018) Clinical applications of bone tissue engineering in orthopedic trauma. Curr Pathobiol Rep 6:99-108

11. Xue P-P, Yuan J, Yao Q et al (2020) Bioactive factors-imprinted scaffold vehicles for promoting bone healing: the potential strategies and the confronted challenges for clinical production. BIO Integr 1:37-54

12. Hutmacher DW, Holzapfel BM, De-Juan-Pardo EM et al (2015) Convergence of regenerative medicine and synthetic biology to develop standardized and validated models of human diseases with clinical relevance. Curr Opin Biotechnol 35:127-132 
13. Murphy MK, MacBarb RF, Wong ME et al (2013) Temporomandibular disorders: a review of etiology, clinical management, and tissue engineering strategies. Int J Oral Maxillofac Implants 28:e393-e414

14. Naik C, Srinath N, Ranganath MK et al (2020) Evaluation of polycaprolactone scaffold for guided bone regeneration in maxillary and mandibular defects: a clinical study. Natl J Maxillofac Surg 11:207-212

15. Davies JE, Matta R, Mendes VC et al (2010) Development, characterization and clinical use of a biodegradable composite scaffold for bone engineering in oro-maxillo-facial surgery. Organogenesis 6:161-166

16. Prasadh S, Wong RCW (2018) Unraveling the mechanical strength of biomaterials used as a bone scaffold in oral and maxillofacial defects. Oral Sci Int 15:48-55

17. Zhou H, Lee J (2011) Nanoscale hydroxyapatite particles for bone tissue engineering. Acta Biomater 7:2769-2781

18. Wei G, Ma PX (2004) Structure and properties of nanohydroxyapatite/polymer composite scaffolds for bone tissue engineering. Biomaterials 25:4749-4757

19. Babilotte J, Martin B, Guduric V et al (2021) Development and characterization of a PLGA-HA composite material to fabricate 3D-printed scaffolds for bone tissue engineering. Mater Sci Eng C 118:111334

20. Place TL, Domann FE, Case AJ (2017) Limitations of oxygen delivery to cells in culture: an underappreciated problem in basic and translational research. Free Radical Biol Med 113:311-322

21. Gaspar DA, Gomide V, Monteiro FJ (2012) The role of perfusion bioreactors in bone tissue engineering. Biomatter 2:167-175

22. Yousefi A-M, Liu J, Sheppard R et al (2019) I-Optimal design of hierarchical 3D scaffolds produced by combining additive manufacturing and thermally induced phase separation. ACS Appl Bio Mater 2:685-696

23. Yousefi AM, Powers J, Sampson K et al (2020) In vitro characterization of hierarchical 3D scaffolds produced by combining additive manufacturing and thermally induced phase separation. J Biomater Sci Polym 32:1-23

24. Liu J, Zhang J, James PF et al (2019) I-Optimal design of poly(lactic-co-glycolic) acid/hydroxyapatite three-dimensional scaffolds produced by thermally induced phase separation. Polym Eng Sci 59:1146-1157

25. Grayson WL, Marolt D, Bhumiratana S et al (2011) Optimizing the medium perfusion rate in bone tissue engineering bioreactors. Biotechnol Bioeng 108:1159-1170

26. BioWest-MEM Alpha w/ L-Glutamine w/o Ribonucleosides w/o Deoxyribonucleosides. DOI: L0475 Safety data sheet.

27. Tuan HS, Hutmacher DW (2005) Application of micro CT and computation modeling in bone tissue engineering. Comput Des 37:1151-1161

28. Sun L, Parker ST, Syoji D et al (2012) Direct-write assembly of 3D silk/hydroxyapatite scaffolds for bone co-cultures. Adv Heal Mater 1:729-735
29. Zhang R, Ma PX (1999) Poly(alpha-hydroxyl acids)/hydroxyapatite porous composites for bone-tissue engineering. I. Preparation and morphology. J Biomed Mater Res 44:446-455

30. Saito E, Liao EE, Hu WW et al (2013) Effects of designed PLLA and 50:50 PLGA scaffold architectures on bone formation in vivo. $J$ Tissue Eng Regen Med 7:99-111

31. Ng R, Zang R, Yang KK et al (2012) Three-dimensional fibrous scaffolds with microstructures and nanotextures for tissue engineering. RSC Adv 2:10110-10124

32. McKenna E, Klein TJ, Doran MR et al (2020) Integration of an ultra-strong poly(lactic-co-glycolic acid) (PLGA) knitted mesh into a thermally induced phase separation (TIPS) PLGA porous structure to yield a thin biphasic scaffold suitable for dermal tissue engineering. Biofabrication. https://doi.org/10.1088/17585090/ab4053

33. Yu NYC, Schindeler A, Peacock L et al (2013) Modulation of anabolic and catabolic responses via a porous polymer scaffold manufactured using thermally induced phase separation. Eur Cells Mater 25:190-203

34. Stolberg S, McCloskey KE (2009) Can shear stress direct stem cell fate? Biotechnol Prog 25:10-19

35. Engler AJ, Sen S, Sweeney HL et al (2006) Matrix elasticity directs stem cell lineage specification. Cell 126:677-689

36. Jiao J, Peng C, Li C et al (2021) Dual bio-active factors with adhesion function modified electrospun fibrous scaffold for skin wound and infections therapeutics. Sci Rep 11:1-13

37. Lao L, Wang Y, Zhu Y et al (2011) Poly(lactide-co-glycolide)/ hydroxyapatite nanofibrous scaffolds fabricated by electrospinning for bone tissue engineering. J Mater Sci Mater Med 22:1873-1884

38. Wood K, Sampson K, James PF, et al. (2020) The effect of argon plasma irradiation on $3 \mathrm{~d}$ scaffolds for bone tissue engineering. In: SPE ANTEC Proceedings. pp. 1-5

39. Bin SS, Keong TK, Cheng CH et al (2013) Tricalcium phosphate/ hydroxyapatite (TCP-HA) bone scaffold as potential candidate for the formation of tissue engineered bone. Indian J Med Res 137:1093-1101

40. Zanetti A, McCandless G, Chan J et al (2015) Characterization of novel akermanite: poly- $\epsilon$-caprolactone scaffolds for human adipose-derived stem cells bone tissue engineering. J Tissue Eng Regen Med 9:389-404

41. Akbarzadeh R, Minton JA, Janney CS et al (2015) Hierarchical polymeric scaffolds support the growth of MC3T3-E1 cells. J Mater Sci Mater Med. https://doi.org/10.1007/s10856-015-5453-z

42. Flaherty T, Tamaddon M, Liu C (2021) Micro-computed tomography analysis of subchondral bone regeneration using osteochondral scaffolds in an ovine condyle model. Appl Sci 11:1-14

Publisher's Note Springer Nature remains neutral with regard to jurisdictional claims in published maps and institutional affiliations. 